\title{
A Quantitative Analysis of Unemployment Benefit Extensions
}

\author{
Makoto Nakajima* \\ November 8, 2011 \\ First draft: January 19, 2010
}

\begin{abstract}
This paper measures the effect of the ongoing extensions of unemployment insurance (UI) benefits on the unemployment rate using a calibrated structural model that features job search and consumption-saving decisions, skill depreciation, UI eligibility, and UI benefit extensions that capture what has happened in response to the recent downturn. I find that the extensions of UI benefits contributed to an increase in the unemployment rate by 1.4 percentage points, which is about 30 percent of an observed increase between the periods 2005-2007 and 2009-2011 (4.8 percent). Among the remaining 3.4 percentage points, 2.5 percentage points are due to the large increase in the separation rate, while the reduced job-finding rate due to lower productivity contributes 0.9 percentage point. Moreover, the contribution of the UI benefit extensions to the elevated unemployment rate increased from 2009 to 2011; while the number of vacancies has been recovering, the unemployment rate has remained elevated because of the successive extensions. The last extension in December 2010 has moderately slowed down the recovery of the unemployment rate. Specifically, the model indicates that the last extension keeps the unemployment rate higher by 0.6 percentage point during 2011.
\end{abstract}

JEL Classification: J64, J65, E24, D91

Keywords: Unemployment Insurance, Extended Benefits, Labor Market, Search, Consumption Smoothing

${ }^{*}$ Research Department, Federal Reserve Bank of Philadelphia. Ten Independence Mall, Philadelphia, PA 19106. E-mail: makoto.nakajima@phil.frb.org. An earlier and simpler version of the paper was circulated under the title "Unemployment Insurance and Unemployment Benefits." I thank Satyajit Chatterjee for his valuable comments as well as encouragement and Shigeru Fujita for stimulating discussions. I also thank Yongsung Chang, the anonymous referee, and seminar participants at the Macroeconomics Conference at Hitotsubashi University, the 2011 Midwest Macro Meeting, the 2011 Society of Economic Dynamics Annual Meeting, and the 2011 Asian Meeting of the Econometric Society for helpful comments. The views expressed here are those of the author and do not necessarily reflect the views of the Federal Reserve Bank of Philadelphia or the Federal Reserve System. 


\section{Introduction}

This paper measures the effect of the ongoing extensions of unemployment insurance (UI) benefits on the unemployment rate using a calibrated structural model of job search. Facing the most severe recession since the Great Depression, the U.S. government enacted a series of extensions of UI benefits that provide an unemployed worker with a maximum of 99 weeks of UI benefits, compared with the regular duration of 26 weeks. While these extensions are one of the responses to the unemployment rate that reached 10 percent in late 2009, which was the second time this happened in postwar U.S. history (the other time was 1982-83), it is also possible that the extensions themselves contributed to the rising unemployment rate through the incentive effect - encouraging jobless workers to remain unemployed so that they received the UI benefits for an extended duration and by discouraging the unemployed to search for a job intensively.

Although there have been other attempts to measure the effect of UI benefit extensions on the unemployment rate, this paper is the only one that uses a structural model to answer the question. The structural approach employed in this paper has two distinct advantages. First, although the maximum duration of 99 weeks is often seen in the headlines, it does not mean that all unemployed workers are eligible for the maximum duration. To the contrary, the maximum duration of UI benefits for each jobless worker is increased gradually with a series of extensions. Moreover, the extensions are temporary; many unemployed workers cannot receive 99 weeks of benefits. Using a structural model and replicating the extensions in the model allow me to take into account the gradual and temporary nature of the extensions. Second, with a calibrated structural model at hand, I can implement counterfactual experiments. For example, I will evaluate how the last extension in December 2010 affects the path of the unemployment rate in the future.

I find that the ongoing extensions of UI benefits contributed to an increase in the unemployment rate by 1.4 percentage points. Since the unemployment rate went up by 4.8 percentage points, from 4.8 percent during 2005-2007, before the recent downturn started, to 9.6 percent during 2009-2011, the contribution of the series of UI benefit extensions is 29 percent. The remaining 3.4 percentage points are due to deteriorating economic conditions. Among the 3.4 percentage points, 2.5 percentage points are due to the large increase in the separation rate, while the staggering hiring due to lower aggregate productivity contributes by 0.9 percentage point. Moreover, the contribution of the UI benefit extensions to the elevated unemployment rate increased from 2009 to 2011; while the number of vacancies has been recovering, the unemployment rate has remained elevated because of the successive UI benefit extensions. I also find that the last extension has moderately slowed down the recovery of the unemployment rate; the model indicates that the last extension in December 2010 kept the unemployment rate higher, by 0.6 percentage point on average during 2011. If a new and equally generous UI benefit extension were to be enacted, we would expect a similar effect on the unemployment rate.

There is a long history of empirical literature that tries to quantify the effect of changes of the level and duration of UI benefits on unemployment duration. To the best of my knowledge, all studies, many of which I cover in Section 6.2, found that the duration of unemployment is longer (and thus the unemployment rate is higher) if the amount of UI benefits is higher or 
the duration of UI benefits is longer. ${ }^{1}$ Although these empirical results indicate a significant effect of the current substantial UI benefit extensions on the unemployment rate, there are only a small number of studies that quantify the effect of the ongoing UI benefit extensions on the unemployment rate. Two recent attempts are Valletta and Kuang (2010) and Fujita (2010b). Both use an empirical approach as in the existing literature to quantify the effect of UI benefit extensions on the unemployment rate. The number obtained in the current paper (1.4 percentage points) is close to the upper end of the available estimates obtained by these studies. Valletta and Kuang (2010) use the Current Population Survey (CPS) and measure the increase in the number of involuntary job losers as well as the average duration of unemployment of the job losers during the recent downturn in order to quantify the impact that UI benefit extensions have on the unemployment rate. The increase in the number of involuntary job losers affects the unemployment rate strongly because they tend to stay in the labor force and search for a job. They conclude that the UI benefit extensions contributed a modest 0.4 percentage point to the unemployment rate when it reached 10 percent. Since they do not explicitly consider the behavioral channel through which the job search intensity is discouraged by generous UI benefits, their number probably underestimates the overall impact of the extensions. Moreover, since the contribution of the UI benefit extensions to the unemployment rate has been increasing according to my model, the difference between their results, which correspond to the earlier period of the last recession, and my results, which are the average during 2009-2011, is smaller than the headline numbers suggest. Fujita (2010b) estimates the exit rates from unemployment during 2004-2007 and during 2009-2010 and uses the changes in the exit rates to quantify the effect of UI benefit extensions on the unemployment rate. He finds that UI benefit extensions increased the unemployment rate by $0.8-1.8$ percentage points. He also quantifies the relative importance of the lower job-finding rate (exit to employment) and the lower probability of exiting the labor force (exit to out-of-labor-force) and finds that the latter was much less significant. His findings support the abstraction of the labor force participation decision in the model used in this paper.

The model used in this paper is based on the model developed by Mortensen (1977) and Chetty (2008). While the model abstracts from the decision of accepting an offer, it is extended in the following ways: First, a stylized version of UI benefit extensions is introduced and the equilibrium transition path involving multiple policy changes and the time-varying separation rate and aggregate productivity is solved. Second, skill depreciation during unemployment spells is introduced. Third, eligibility for UI benefits is taken into account to capture the fact that less than half of the unemployed are receiving UI benefits in normal times. Fourth, as in Chetty (2008), workers are risk-averse and subject to a borrowing constraint. Finally, the number of vacancy postings is endogenized with the firm's decision to enter the labor market.

Recently, quantitative macroeconomic models with labor market frictions have been extensively developed to investigate various labor market issues. The current paper is a part of this growing branch of literature. Reichling (2007) studies the optimal UI policy using a quantitative macroeconomic model with incomplete markets. Ljungqvist and Sargent (1998) emphasize the turbulence effect in explaining the U.S.-European difference in labor market dynamics. The

\footnotetext{
1 Krueger and Mueller (2010) find that unemployed workers in a state with a higher maximum weekly UI benefit amount tend to spend less time searching for a job.
} 
turbulence effect is important in evaluating the effect of UI benefit extensions as well; as the average duration of unemployment increases, skill depreciation during unemployment spells is accelerated. Not only does the fast skill depreciation reduce the productivity and income of workers on average, the skill depreciation itself slows down the hiring process as firms offer fewer vacancies to workers with depreciated skills. Fujita (2011) incorporates skill depreciation in the standard labor search framework. Acemoglu and Shimer (2000) analyze the positive match quality effect of a more generous UI benefit using a macroeconomic model. As workers become less desperate with the more generous UI benefits, they can wait for better matches. Krusell et al. (2010), Nakajima (forthcoming), and Bils et al. (2011) study the business cycle properties of the macroeconomic model with labor market frictions. Recently, Landais et al. (2011) and Mitman and Rabinovich (2011) investigate the optimal UI policy over the business cycles.

The rest of the paper proceeds as follows. In Section 2, I describe the ongoing extensions of UI benefits. Section 3 presents the model. Section 4 discusses how the model is calibrated. Section 5 comments on the computational methods used to solve the model. Details of the computation can be found in the Computational Appendix. Section 6 presents the results based on the steadystate analysis. Section 7 presents the main results of the paper, using equilibrium transition analysis. Section 8 investigates the sensitivity of the main results to model assumptions. Section 9 concludes.

\section{Unemployment Benefit Extension: Facts}

Although standard UI benefits last 26 weeks in most states, the government often enacts extensions of UI benefits during economic downturns. ${ }^{2}$ There are two types of extensions, both of which have been activated during the recent downturn. Remember that, under both types of extensions, the level of benefits is the same as the level of the regular benefits.

The first type of extension is called the extended benefits (EB) program. It is a permanent program that is automatically activated for a state whenever the unemployment rate of that state reaches a certain level. ${ }^{3}$ The EB program provides an additional 13 or 20 weeks of UI benefits for most states if the unemployment rate of the state exceeds 6.5 percent or 8.0 percent, respectively. Currently, a majority of states qualify for the 20 weeks of extended UI benefits under the EB program. To give an idea of the approximate timing when the extended UI benefits under the EB program became available, let's use the national average unemployment rate. The national average unemployment rate exceeded the threshold for the 13 weeks of extended benefits under the EB program (6.5 percent) in November 2008. The national unemployment rate went above the threshold for 20 weeks of extended benefits under the EB program (8.0 percent) in March 2009. Since then, the national average unemployment rate remained above the threshold for the 20-week UI benefit extension.

The second type of extension is not automatic; Congress enacts this type of extension temporarily in response to severe downturns. The latest program in this category, the Emergency Unemployment Compensation program (EUC08), represents the eighth time Congress has created such a program. ${ }^{4}$ EUC08 was signed into law in June 2008. Initially, the maximum duration

2 This section is based on the description of UI benefit extensions by Fujita (2010a).

3 To be more precise, the three-month average of the state unemployment rate is used.

4 Congress enacted temporary extensions of UI benefits in 1958, 1961, 1971, 1974, 1982, 1991, 2002, and 2008 so 
Table 1: Recent Extensions of UI Benefits. ${ }^{1}$

\begin{tabular}{ll}
\hline Date & Description \\
\hline June 30,2008 & The EUC08 program was introduced. The maximum duration of the \\
& $\begin{array}{l}\text { additional benefits under the program was } 13 \text { weeks. It is called Tier-1 } \\
\text { of extended UI benefits. The expiration date was set for March 28, } \\
\\
2009 .\end{array}$
\end{tabular}

November 21, 2008 The maximum entitlement under Tier-1 was extended from 13 to 20 weeks. Tier-2, which provides a maximum of 13 weeks of additional UI benefits in states with an unemployment rate of at least 6 percent, was introduced. The expiration date remained at March 28, 2009.

February 17, 2009 As part of the American Economic Recovery and Reinvestment Act, the expiration date was pushed back to December 26, 2009. The act also included a provision to pay an additional weekly benefit of $\$ 25$ to those receiving extended UI benefits under the EUC08.

November 6, 2009 The duration of additional UI benefits was substantially expanded. Tier-1 remained 20 weeks, but Tier- 2 was expanded to 14 weeks and no longer depends on the state unemployment rate. A newly introduced Tier-3 provides an additional 13 weeks of benefits for those in states with an unemployment rate of at least 6 percent, and another newly introduced Tier- 4 provides an additional six weeks for states with an unemployment rate higher than 8.5 percent. The expiration date was fixed at December 26, 2009.

December 19, 2009 The expiration date was pushed back to February 28, 2010, without changing the existing tier structure.

March 2, $2010 \quad$ The expiration date was pushed back to March 31, 2010, without changing the existing tier structure.

April 15, $2010 \quad$ The expiration date was pushed back to June 2, 2010, without changing the existing tier structure.

June 22, $2010 \quad$ The expiration date was pushed back to November 30, 2010, without changing the existing tier structure.

December 17, 2010 The expiration date was pushed back to January 3, 2012 without changing the existing tier structure.

${ }^{1}$ Based on Fujita (2010a), "The Chronology of the Emergency Unemployment Compensation Program (EUC08)."

of extended UI benefits under the program was 13 weeks, but it has been extended several times since then. As of January 2011, the EUC08 and subsequent expansions provided extended benefits for up to 53 weeks. Combining the extensions under EUC08 (53 weeks) with the regular benefits (26 weeks) and the EB (20 weeks), an unemployed worker is entitled to UI benefits for

far. See Whittaker (2008) for more details about past extensions. 
up to 99 weeks in total. See Table 1 for a summary of the original EUC08 and the subsequent expansions and extensions.

Typically, the additional UI benefits under the EB program can be used after an unemployed worker exhausts all the tiers under the EUC08. Therefore, I refer to the additional benefits under the EB program as Tier-5. Also for ease of notation, I will refer to the regular UI benefits as Tier-0.

Let me make three remarks about the nature of the ongoing extensions implemented in response to the recent downturn. First, they are very generous compared with past extensions. For example, before the current extensions, the most generous ones in the past provided about 60 weeks of benefits compared with the current extensions of up to 99 weeks.

Second, the EUC08 was gradually expanded. It is not as if unemployed workers were eligible for 99 weeks of UI benefits from the time the EUC08 was first enacted. Instead, as of June 2008 when the EUC08 was introduced, the available extension was only 13 weeks of additional UI benefits. It took a year and a half from the time the first EUC08 was enacted until the maximum of 99 weeks of additional UI benefits became available. In the main experiment of the paper, I will take into account this gradual expansion of the ongoing extensions.

Third, although the number 99 is widely cited to describe the generosity of the ongoing extensions, not all unemployed workers actually enjoy the full 99 weeks of extended UI benefits. In order to understand how many weeks of extended UI benefits an unemployed worker is actually entitled to, one needs to understand the tier structure and what the expiration date means. For example, let's consider the extension enacted on June 22, 2010. The extension did not change the existing tier structure, but it pushed back the expiration date by 23 weeks to November 30, 2010. This means that an unemployed worker cannot move up from the tier he is in as of November 30, 2010. If he is receiving UI benefits under Tier-1 as of November 30, the end of Tier-1 is the end of the UI benefits for him. In other words, except for unemployed workers who are close to exhausting Tier-0 (the regular UI benefits of 26 weeks), the unemployed workers who were receiving Tier-0 benefits as of the implementation of the extension (June 22) can only go up to Tier-1, as they will never exhaust Tier-1 benefits by the expiration date. Those who just started receiving the regular UI benefits actually will not qualify even for Tier-1 under the extension because they will not exhaust the 26-week regular benefit (Tier-0) by the expiration date, which is 23 weeks ahead of the day of the extensions. Considering that the extensions, except for the last one, pushed back the deadline by 11.0 weeks on average, and each tier adds on average 14.6 extra weeks of UI benefits, each extension, except for the last one, allows the majority of unemployed workers to move up just one tier from the one they are in at the time of each extension. Meanwhile, the last extension, enacted in December 2010, pushed back the deadline by 55 weeks. This means that unemployed workers can go up by about three tiers from the one they are in at the time of each extension.

\section{Model}

I start by describing the environment and then move on to characterize the worker's and the firm's problem and define the equilibrium. Since I will characterize the worker's and the firm's problem recursively, I omit the time script from variables and use a prime to denote the variables in the next period wherever appropriate. At the end of this section, I will define the competitive 
equilibrium and then the steady-state competitive equilibrium. I conduct the analysis based on comparison of steady states in Section 6, and then move on to the analysis using the equilibrium transition in Section 7.

\subsection{Preferences}

Time is discrete and infinite and starts from period 1. The model is inhibited by a mass of infinitely lived workers and firms. Workers maximize expected lifetime utility. Utility is time separable, with the time discount factor $\beta$. Period utility depends on the consumption of goods, $c$, and search intensity, $s$. The expected lifetime utility of a worker takes the following form:

$$
\mathbb{E}_{0} \sum_{t=1}^{\infty} \beta^{t} u\left(c_{t}, s_{t}\right)
$$

Firms are risk neutral and discount future profits at the interest rate $r$. Firms maximize their expected discounted sum of profits.

\subsection{Technology and Wage Determination}

A matched pair of a worker and a firm can produce. The output is characterized by:

$$
y_{t}=z_{t} h
$$

where $z_{t}$ is the aggregate productivity, and $h \in H=\left\{h_{1}, h_{2}, \ldots, h_{H}\right\}$, where $h_{1}<h_{2} \ldots<h_{H}$ is the skill level of the worker. $z_{t}$ is constant $\bar{z}$ in the steady state, while it is time-varying in the economy with an equilibrium transition. $h$ changes stochastically. In particular, while employed, a worker with the skill level $h_{i}$ acquires a new skill and his skill level becomes $h_{i+1}$ with probability $p_{+}^{h}$. On the other hand, while unemployed, a worker with the skill level $h_{i}$ experiences a skill depreciation, and his skill level becomes $h_{i-1}$ with probability $p_{-}^{h}$. The acquisition and depreciation of skills, together with the turbulence, are important factors in explaining the persistently high unemployment in Europe in Ljungqvist and Sargent (1998). More generally, human capital changes according to a transition probability $\pi_{u, h, h^{\prime}}^{h}$, where $u$ represents the employment status of the worker. $u=0$ denotes employment, and $u>0$ denotes the duration of unemployment.

The output $y_{t}$ is shared between the worker and the firm. The wage the worker receives is assumed to be $w\left(z_{t}\right) h$. Wage per efficiency unit, $w\left(z_{t}\right)$, is assumed to be a function of the aggregate productivity, in order to capture the property of the data that the average wage moves with productivity, but is much less volatile (sticky real wage). Generally, if the wage is modeled as the outcome of bargaining between the firm and the worker in a match, the wage depends on all the individual characteristics of the firm and the worker, including the level of asset holdings of the worker. However, it was found that the bargaining outcome is not too sensitive to the level of asset holdings. For a more general bargaining setup, see Krusell et al. (2010) and Nakajima (forthcoming). The profit of a firm matched with a type- $h$ worker can be characterized by $\left(z_{t}-w\left(z_{t}\right)\right) h$.

\subsection{Labor Market}

The employment status of a worker is represented by $u$. Workers can be either employed $u=0$ or unemployed $u>0$. When a worker is unemployed, $u$ represents the length of the ongoing 
unemployment spell: how many periods the worker has been unemployed. An unemployed worker receives UI benefits if he is eligible and can search for a job. Workers with different productivity levels search in different markets. ${ }^{5}$ Since the individual productivity is characterized by $h$, and the worker's wage and the firm's profits also depend solely on $h$ (and aggregate productivity $z_{t}$ ), it is natural to assume that there are separate markets for each $h$. Let's denote $s, S^{h}$, and $V^{h}$ as the individual search effort, aggregate search effort in the $h$-market, and the number of vacancies posted in the $h$-market, respectively. There is a matching function that takes $S^{h}$ and $V^{h}$ and outputs the number of new matches created, $M^{h}$. Specifically:

$$
M^{h}=m\left(S^{h}, V^{h}\right)
$$

Assuming constant returns to scale matching function, the matching probabilities per search effort, $f^{h}$, and per vacancy, $d^{h}$, can be functions of labor market tightness, $\theta^{h}=V^{h} / S^{h}$, as shown below:

$$
\begin{aligned}
& f^{h}=\frac{m\left(S^{h}, V^{h}\right)}{S^{h}}=m\left(1, \theta^{h}\right) \\
& d^{h}=\frac{m\left(S^{h}, V^{h}\right)}{V^{h}}=m\left(1 / \theta^{h}, 1\right)
\end{aligned}
$$

When an unemployed worker of type $h$ searches with an intensity $s$, the probability of finding a job for a worker is $f^{h} s$. The labor market tightness for each market $h$ is the key equilibrium object.

Job separation is exogenous and characterized by separation rate $\lambda_{t}$. The separation rate is the same across all workers. It is constant $\bar{\lambda}$ in a steady-state equilibrium but can be time-varying in an equilibrium with transition. Firms can enter any of the $h$-markets by posting a vacancy at the flow cost of $\kappa$.

\subsection{Financial Market}

Workers can save and borrow to smooth consumption over time. Markets are incomplete: workers cannot trade state-contingent securities. Let $k$ denote the asset holdings of a worker. The interest rate associated with the asset is constant at $r$. Workers are subject to a borrowing constraint $k \geq \underline{k}$.

\subsection{Unemployment Insurance Program}

The government runs the UI program. The UI program is characterized by $\{b, q, B(x, a)\}$, where $b$ is the amount of UI benefits, $q$ is the amount of non-UI benefits that are available for unemployed workers who are either (i) ineligible for UI benefits or (ii) eligible but have exhausted UI benefits, and $B(x, a)$ represents how many periods a worker of type $a$ in Tier- $x$ is eligible to receive UI benefits. $a$ represents the eligibility status for UI benefits. Workers with $a=0$ are ineligible and

5 Alternatively, I can assume random matching for all types of workers. However, the difference in the average duration of unemployment across different income groups and the fact that the overall average job-finding rate is declining in the unemployment spell are consistent with the assumption that workers with different productivity face different markets and thus different job-finding rates. More detailed discussion can be found in Section 6 . 
cannot receive any UI benefits. In other words, $B(x, 0)=0$ for $\forall x$. Workers with $a=1$ in Tier- $x$ are eligible and can receive UI benefits until $B(x, 1)$ periods. If a worker with the eligibility status $a$ is unemployed for $u(>0)$ periods, and the worker is in Tier- $x$, the worker receives UI benefits $b$ if $u \leq B(x, a)$, and the worker receives $q$ if $u>B(x, a)$. $x$ takes the value between 0 and $X$. As will be clear when calibrating the model, $x=0$ indicates the regular UI benefits, and $x>0$ indicates that a worker is eligible for extended UI benefits.

Notice that $b$ and $q$ can include non-monetary benefits from unemployment, such as extra time for leisure or utility from home production, as well. Hagedorn and Manovskii (2008) show that if $b$ is closer to the average wage than implied by the replacement rate of monetary UI benefits, i.e., the value of unemployment is close to the value of employment, the model with labor market search and matching can replicate the observed high volatility of unemployment and vacancies. Nakajima (forthcoming) shows that the real business cycle model with labor market frictions and a labor-leisure decision can be calibrated to generate a strong amplification because of the value of extra leisure time in unemployment. Bils et al. (2011) also incorporate non-monetary benefits from unemployment. I will come back to this issue when calibrating the model.

Furthermore, for notational convenience, I define a function $\xi(x, u, a)$, which specifies the benefits available for a worker of type $(u, x, a)$. Specifically:

$$
\xi(x, u, a)= \begin{cases}0 & \text { if } u=0 \\ b & \text { if } 0<u \leq B(x, a) \\ q & \text { if } u>B(x, a)\end{cases}
$$

The eligibility status $a$ does not change during an unemployment spell, i.e., $a^{\prime}=a$ if $u>0$. When a worker finds a new job and becomes employed $(u=0)$, the worker loses eligibility for UI benefits, i.e., $a$ becomes 0 upon starting a new job. $\pi_{a, a^{\prime}}^{a}$ is the transition probability with respect to $a$ for employed $(u=0)$ workers. An employed worker without eligibility $(a=0)$ becomes eligible $\left(a^{\prime}=1\right)$ with a probability $\pi_{0,1}^{a}$. This is a simple way to capture that a worker becomes eligible for UI benefits after working for a certain period and contributing sufficiently to the UI program. Once an employed worker becomes eligible $(a=1)$, the worker never loses eligibility until the worker loses a job and finds a new job.

\subsection{UI Benefit Extension}

An extension of UI benefits gives an additional duration of UI benefits for the unemployed who are exhausting or have exhausted the existing benefits under the current Tier- $x$. An extension of UI benefits is modeled as shifting $x$ of unemployed workers, in particular to a higher $x$ that is associated with a longer duration of UI benefits. Meanwhile, when workers become employed, it is assumed that $x$ of the workers revert to 0 (i.e., no additional UI benefits in the future once the worker becomes employed). As for workers who are employed at the time of an extension, I assume that those workers do not benefit from extensions, for simplicity. In reality, some workers who lose their jobs relatively soon after an extension is implemented could benefit from the extension. However, since there is no separation decision and the separation rate will be calibrated to be low, very few employed workers benefit from an extension. Therefore, no extension for employed workers at the time of an extension is a reasonable assumption.

Specifically, suppose there are $J$ extensions. I will denote the initial state of the economy as the extension-0 (no extension), and $j=1,2, \ldots, J$ extensions are announced and implemented 
one by one. An extension $j$ is defined by a triplet $\left\{\tau_{j}, \widetilde{\tau}_{j}, \chi_{j, t}(x, u, a)\right\} . \tau_{j}$ is the period in which the extension is announced, while $\widetilde{\tau}_{j} \geq \tau_{j}$ is the period in which the extension is implemented. Since the extension- 0 is the initial state, $\tau_{0}=\widetilde{\tau}_{0}=1$. The difference between $\tau_{j}$ and $\widetilde{\tau}_{j}$ could be important; for example, in the recent slowdown, extensions of UI benefits are typically discussed within the government long before their actual implementation. Therefore, it is likely that potential beneficiaries of the extended UI benefits take into account the likelihood that extended UI benefits will become available soon, when they make the search intensity decision. Using $\tau_{j} \leq \widetilde{\tau}_{j}$, I can introduce such anticipation effect. Also notice that extensions are announced and implemented sequentially, and extensions are a complete surprise when announced. Specifically, in period $t<\tau_{\bar{j}}$ for some $\bar{j}$, extensions $j=\bar{j}, \bar{j}+1, \ldots, J$ are unknown to agents. Finally, $x^{\prime}=\chi_{j, t}(x, u, a)$ is a function that determines how $x$ of a type- $(x, u, a)$ worker is changed by the extension $j$ in period $t$. For example, with the extension $j$, which upgrades eligible workers who are receiving UI benefits under the Tier-0 to Tier-3 in period $154, \chi_{j, 154}(0, u, 1)=3$ for $\forall u>0$. For periods $t \neq \widetilde{\tau}_{j}, x$ is unchanged, i.e., $\chi_{j, t}(x, u, a)=x$. For the extension- 0 , there is no extension by definition. Therefore, $\chi_{0, t}(x, u, a)=x$ for $\forall t, x, u, a$.

\subsection{Worker's Problem}

In this section, the problem of a worker is characterized using a recursive formulation. The individual state of a worker is represented by $(x, h, u, a, k)$. The problem of an employed $(u=0)$ worker can be defined recursively as follows:

$$
\begin{aligned}
& W_{j, t}(x, h, u=0, a, k)= \\
& \max _{k^{\prime} \geq \underline{k}}\left\{u(c, 0)+\beta \sum_{h^{\prime}} \sum_{a^{\prime}} \pi_{u, h, h^{\prime}}^{h} \pi_{a, a^{\prime}}^{a}\left(\left(1-\lambda_{t}\right) V_{j, t+1}\left(x^{\prime}, h^{\prime}, 0, a^{\prime}, k^{\prime}\right)+\lambda_{t} W_{j, t+1}\left(x^{\prime}, h^{\prime}, 1, a^{\prime}, k^{\prime}\right)\right)\right\}
\end{aligned}
$$

subject to:

$$
\begin{aligned}
& c+k^{\prime}=(1+r) k+w\left(z_{t}\right) h \\
& x^{\prime}=\chi_{j, t+1}(x, u, a)
\end{aligned}
$$

$j$ is the last extension announced. In other words, the future extensions $j+1, j+2, \ldots, J$ are unexpected for the worker. $t$ is the current period. Equations (7), (8), and (9) are the Bellman equation, the budget constraint, and the transition of $x$ associated with the extension $j$, respectively. Notice three things: First, employment status $u$ does not change at $u=0$ if the worker remains employed, but changes to $u=1$ (first period of unemployment) if separation occurs with probability $\lambda_{t}$. Second, search intensity $(s)$ is zero, i.e., there is no job search or job-to-job transition. Third, workers expect $x$ to change according to equation (9) and do not expect further extensions.

Similarly, the problem of an unemployed worker with the unemployment duration of $u>0$ 
can be defined recursively as follows:

$$
\begin{aligned}
& W_{j, t}(x, h, u>0, a, k)= \\
& \max _{k^{\prime} \geq \underline{k}, s}\left\{u(c, s)+\beta \sum_{h^{\prime}} \pi_{u, h, h^{\prime}}^{h}\left(f_{j, t}^{h} s W_{j, t+1}\left(0, h^{\prime}, 0,0, k^{\prime}\right)+\left(1-f_{j, t}^{h} s\right) W_{j, t+1}\left(x^{\prime}, h^{\prime}, u+1, a, k^{\prime}\right)\right)\right\}
\end{aligned}
$$

subject to:

$$
\begin{aligned}
& c+k^{\prime}=(1+r) k+\xi(x, u, a) \\
& s \in\left[0,1 / f_{j, t}^{h}\right]
\end{aligned}
$$

and equation (9). Equation (10) is the Bellman equation. Equation (11) is the budget constraint. Equation (12) is the constraint for the search intensity decision; $s$ is bounded from above by $1 / f_{j, t}^{h}$ to make sure that the probability of finding a job never exceeds 1 . Notice four things: First, the tier of a worker $(x)$ who finds a new job changes to $x^{\prime}=0$ (ineligible for an extension). Second, $a^{\prime}$ becomes 0 if the worker finds a job, while $a^{\prime}$ remains $a$ if the worker fails to land a job. Third, it is necessary to know the sequence of labor market tightness $\left\{\theta_{j, t}^{h}\right\}_{t=\tau_{j}}^{\infty}$ to know the sequence of the job-finding rate. Fourth, the labor market tightness depends not only on $t$, but also on $j$. When solving for an equilibrium, one needs to solve for a sequence of the labor market tightness for all $j$, since the sequence of the labor market tightness changes when $j$ changes (a new UI benefit extension is announced).

The Bellman equations (7) and (10) characterize the optimal value functions $W_{j, t}(x, h, u, a, k)$ and associated optimal decision rules $k^{\prime}=g_{j, t}^{k}(x, h, u, a, k)$ and $s=g_{j, t}^{s}(x, h, u, a, k)$. For notational convenience, let $\mathbf{M}$ be the space of an individual state, i.e., $(x, h, u, a, k) \in \mathbf{M}$. Let $\mathcal{M}$ be the Borel $\sigma$-algebra generated by $\mathbf{M}$, and $\mu$ the probability measure defined over $\mathcal{M}$. I will use a probability space $(\mathbf{M}, \mathcal{M}, \mu)$ to represent a type distribution of heterogeneous workers.

\subsection{Firm's Problem}

The value of a matched firm can be recursively defined as follows: ${ }^{6}$

$$
F_{j, t}(h)=\left(z_{t}-w\left(z_{t}\right)\right) h+\frac{1}{1+r} \sum_{h^{\prime}} \pi_{0, h, h^{\prime}}^{h}\left(1-\lambda_{t}\right) F_{j, t+1}\left(h^{\prime}\right)
$$

As for unmatched firms, free entry of firms is assumed: unmatched firms can enter the labor market by posting a vacancy in any of the $h$-markets at the flow vacancy posting cost of $\kappa$. Therefore, the free entry condition in period $t$ and the known last extension $j$ for market $\bar{h}$ can be denoted as follows:

$$
0=-\kappa+\frac{d_{j, t}^{\bar{h}}}{1+r} \frac{\int_{\mathcal{M}} \mathbb{1}_{h=\bar{h}} \sum_{h^{\prime}} \pi_{1, h, h^{\prime}}^{h} F_{j, t+1}\left(h^{\prime}\right) g_{j, t}^{s}(x, h, u, a, k) d \mu_{j, t}}{\int_{\mathcal{M}} \mathbb{1}_{h=\bar{h}} g_{j, t}^{s}(x, h, u, a, k) d \mu_{j, t}}
$$

\footnotetext{
6 The value of a matched firm depends only on $h$ and aggregate productivity and not on other elements of the type of worker to which a firm is matched because of the assumption that the bargaining outcome is characterized by $w\left(z_{t}\right)$, which does not depend on the individual characteristics of the worker. See also the discussion in Section 3.2.
} 
An unmatched firm pays $\kappa$ to post a vacancy in market $\bar{h}$, and with probability $d_{j, t}^{\bar{h}}$, the vacancy gets matched and the firm becomes matched with a type- $\bar{h}$ worker and starts producing in the next period. The value in the next period is discounted by the interest rate $r$. The last fraction in Equation (14) represents the expected value of the unmatched firm, weighted by the search effort chosen by different types of workers. $\mathbb{1}_{\text {condition }}$ is the indicator function, which takes the value $1(0)$ if the attached condition is satisfied (not satisfied). The indicator function is used to include only the type- $\bar{h}$ workers when calculating the expected value from a match. Equation (14) is a general form, but it can be greatly simplified because the firm's value depends only on $h$ and firms can enter any of the $h$-markets. In particular, the free entry condition (14) can be simplified to the following:

$$
0=-\kappa+\frac{d_{j, t}^{\bar{h}}}{1+r} \sum_{h^{\prime}} \pi_{1, \bar{h}, h^{\prime}}^{h} F_{j, t+1}\left(h^{\prime}\right)
$$

Together with the constant returns to scale of the aggregate matching function, the labor market tightness for market $h$ in period $t$ under the extension $j, \theta_{j, t}^{h}$, can be obtained from the simplified free entry condition (15), which doesn't include the worker's optimal decision rules.

\subsection{Equilibrium}

Suppose that the economy starts from no announced extension $(j=0)$, and there are $J$ extensions announced and implemented sequentially. Each time a new extension $j$ is announced, the sequence of the expected future labor market tightness is going to change. Therefore, it is necessary to solve for the equilibrium sequence of the tightness under all $j=0,1,2, \ldots, J$. I will first define the competitive equilibrium, then move on to define the steady-state competitive equilibrium.

Definition 1 (Competitive equilibrium) Given a sequence of time-varying parameters $\left\{z_{t}, \lambda_{t}\right\}_{t=1}^{\infty}$, $J$ extensions $\left\{\tau_{j}, \widetilde{\tau}_{j}, \chi_{j, t}(x, u, a)\right\}_{j=0}^{J}$, and the initial type distribution of workers $\mu_{0}$, a competitive equilibrium is a sequence of labor market tightness for all markets and under all extensions $\left\{\theta_{j, t}^{h}\right\}_{t=\tau_{j}}^{\infty}$, value functions $W_{j, t}(x, h, u, a, k), F_{j, t}(h)$, optimal decision rules $k^{\prime}=g_{j, t}^{k}(x, h, u, a, k)$, and $s=g_{j, t}^{s}(x, h, u, a, k)$, and probability measures $\left\{\mu_{j, t}\right\}_{t=\tau_{j}}^{\infty}$, such that:

1. For all $j$, given $\left\{\theta_{j, t}^{h}\right\}_{t=\tau_{j}}^{\infty}, W_{j, t}(x, h, u, a, k)$ is a solution to the Bellman equations (7) and (10). $k^{\prime}=g_{j, t}^{k}(x, h, u, a, k)$ and $s=g_{j, t}^{s}(x, h, u, a, k)$ are the associated optimal decision rules for all periods.

2. For all $j$, given $\left\{\theta_{j, t}^{h}\right\}_{t=\tau_{j}}^{\infty}, F_{j, t}(h)$ is a solution to the Bellman equation (13) for all periods.

3. For $j=0$, the initial measure is $\mu_{0}$, while the initial measure is $\mu_{j-1, \tau_{j}}$ for $j>0$. For each of $j=0,1,2, \ldots, J$, given the initial measure, the sequence of the measure of workers $\left\{\mu_{j, t}\right\}_{t=\tau_{j}}^{\infty}$ is consistent with the transition function implied by the stochastic processes for $h$ and $a$; the job turnover process implied by the separation rate $\left\{\lambda_{t}\right\}_{t=1}^{\infty}$; the job-finding rate, which is computed from the labor market tightness $\left\{\theta_{j, t}^{h}\right\}_{t=\tau_{j}}^{\infty}$; the optimal decision rules $s=g_{j, t}^{s}(x, h, u, a, k)$ and $k^{\prime}=g_{j, t}^{k}(x, h, u, a, k)$; and the transition of $x$ characterized by $\left\{\chi_{j, t}(x, u, a)\right\}_{t=\tau_{j}}^{\infty}$. 
4. For all $j$, the sequence of the labor market tightness $\left\{\theta_{j, t}^{h}\right\}_{t=\tau_{j}}^{\infty}$ is consistent with free entry condition (14) for each period and market.

Definition 2 (Steady-state competitive equilibrium) A steady-state competitive equilibrium is a competitive equilibrium where labor market tightness, value functions, optimal decision rules, and type distribution are time-invariant.

\section{Calibration}

Table 2 summarizes the calibration of parameter values. Since the main focus of the model is the labor market status transition, one period is set as one week. Period 1 in the model corresponds to the last week of 2007, which was about the beginning of the last recession. I first calibrate the initial steady state in this section. The initial steady state is the starting point of the transition analysis and is intended to capture the average state of the U.S. economy, especially shortly before the recent recession and the associated unemployment benefit extensions took place. Since I calibrate the steady-state economy, I will omit the time script from all variables below. I will discuss the calibration of the baseline transition path in Section 4.6 and Section 4.7.

\subsection{Preferences}

I use the following separable functional form for the period utility function:

$$
u(c, s)=\frac{c^{1-\sigma}}{1-\sigma}-\gamma \frac{s^{1+\phi}}{1+\phi}
$$

The separability between utility from consumption and (dis-)utility from search intensity is also employed by Chetty (2008). $\sigma$ is calibrated to be 2 , which is the widely accepted value in the literature. $\gamma$ is calibrated such that, on average, $s$, the time spent on job search, is 3.8 percent of disposable time. The target number is provided by Krueger and Mueller (2010), who report that an unemployed person spends on average 32 minutes per day in job search activity. ${ }^{7}$ The calibration strategy yields $\gamma=2.134$. Notice that $\gamma$ is calibrated simultaneously with $\beta$, and $\xi$, to match three targets simultaneously. $\phi$ is the most important parameter because $\phi$ is the key determinant of how search effort responds to a change in benefits of finding a job and benefits of remaining unemployed. I calibrate $\phi$ to be 0.92 . With the calibrated value of $\phi=0.92$, the responses of the average duration of unemployment to changes in the UI policy implied by the model are within the range of available estimates from empirical analysis. I will discuss more on this issue in Section 6. Considering the importance of $\phi$ in driving the main results of the paper, I will investigate the sensitivity of the main results under different values of $\phi$. The discount factor, $\beta$, is calibrated such that 40.2 percent of the unemployed have either zero or a negative amount of assets. This number is computed from the 2005 wave of the Panel Study of Income Dynamics (PSID). The calibration strategy yields $\beta=0.9976$. The weekly interest rate is set at $r=0.0006$, which corresponds to an annual interest rate of 3 percent. The value is used by Acemoglu and Shimer (2000).

\footnotetext{
7 Disposable time per day is 14 hours. This excludes time for sleep and other personal care activities.
} 
Table 2: Summary of Calibration

\begin{tabular}{|c|c|c|}
\hline Parameter & Description & Value \\
\hline$\sigma$ & Coefficient of relative risk aversion & 2.0000 \\
\hline$\gamma$ & Level parameter of disutility from search & 2.1340 \\
\hline$\phi$ & Curvature parameter of disutility from search & 0.9200 \\
\hline$\beta$ & Time discount factor (weekly) & 0.9976 \\
\hline$r$ & Real interest rate (weekly) & 0.0006 \\
\hline $\bar{z}$ & Steady-state level of aggregate productivity & 1.0000 \\
\hline$h_{1}$ & Productivity of low-skilled workers ${ }^{1}$ & 645 \\
\hline$h_{2}$ & Productivity of medium-skilled workers ${ }^{1}$ & 759 \\
\hline$h_{3}$ & Productivity of high-skilled workers ${ }^{1}$ & 893 \\
\hline$\pi_{1, i, i-1}^{h}$ & Probability of skill depreciation during unemployment (weekly) & 0.0667 \\
\hline$\pi_{0, i, i+1}^{h, i, c-1}$ & Probability of skill acquisition during employment (weekly) & 0.0040 \\
\hline $\bar{w}$ & Steady-state level of the bargaining outcome & 0.9700 \\
\hline$\epsilon_{w}$ & Elasticity of wage with respect to productivity & 0.4490 \\
\hline$\xi$ & Level parameter of matching function & 0.6068 \\
\hline$\alpha$ & Curvature parameter of matching function & 0.7200 \\
\hline $\bar{\lambda}$ & Separation rate (weekly) & 0.0028 \\
\hline$\kappa$ & Flow vacancy posting $\operatorname{cost}^{1}$ & 443 \\
\hline$\underline{k}$ & Borrowing limit ${ }^{1}$ & -1000 \\
\hline $\bar{b}$ & UI benefits ${ }^{1}$ & 541 \\
\hline$q$ & non-UI benefits ${ }^{1}$ & 271 \\
\hline$\pi_{0,1}^{a}$ & Probability of becoming eligible for UI benefits (weekly) & 0.005033 \\
\hline
\end{tabular}

\subsection{Technology and Wage Determination}

$\bar{z}$, the steady-state $z_{t}$, is normalized to 1 . I use three $(H=3)$ skill levels. A drop of one level is intended to capture the average skill depreciation during an unemployment spell, and a drop of two levels is intended to represent the skill depreciation of the long-term unemployed. As for the step size of $h$, I use 0.15, i.e., a drop of the skill level from $h_{3}$ to $h_{2}$ or $h_{2}$ to $h_{1}$ corresponds to a 15 percent loss of wages after obtaining the next job. The step size is consistent with Farber (2011), who reports that job losers experience on average about 15 percent of real weekly earnings. Jacobson et al. (1993) and Kambourov and Manovskii (2009) report similar numbers. I set the probability of skill depreciation to be $1 / 15$, based on the average duration of an unemployment spell of 15 weeks. As for the skill accumulation, the probability of climbing up to the next skill level is set at 1/250. Kambourov and Manovskii (2009) report that the first 5 years (250 weeks) of occupational tenure are associated with an increase in wages of 12-20 percent. The productivity level of the medium skill level $h_{2}$ is set at 759 , which is associated with the median wage of workers in the Current Population Survey (CPS) during 2000-2010. 
I assume the following form of the wage function.

$$
w(z)=\exp \left(\log \bar{w}+\epsilon_{w} \log z\right)
$$

where $\bar{w}$ represents the share of output for the worker in the steady state, and $\epsilon_{w}$ represents the elasticity of the average wage with respect to aggregate productivity. I set $\bar{w}=0.97$. The number corresponds to the large size of workers' earnings relative to the firm's profits. Calibration of both Shimer (2005) and Hagedorn and Manovskii (2008) implies a similar value of $\bar{w}$. As for $\epsilon_{w}$, Hagedorn and Manovskii (2008) report that a 1-percent increase in labor productivity is associated with a 0.449 percent increase in real wages. Instead of assuming a particular bargaining like Nash bargaining and calibrating the parameter associated with the bargaining to replicate the elasticity, I assume the wage function directly. ${ }^{8}$

\subsection{Labor Market}

The matching function takes the Cobb-Douglas form, which is widely accepted in the literature.

$$
M=m(S, V)=\xi S^{\alpha} V^{1-\alpha}
$$

The average matching efficiency, $\xi$, is calibrated such that the steady-state unemployment rate is 4.77 percent, which is the average during 2005-2007. The calibration procedure yields $\xi=0.6068$. The curvature parameter of the matching function $\alpha$ is calibrated to be 0.72 , as in Shimer (2005). I will investigate the sensitivity of the main results with respect to a different value of $\alpha$ for the following two reasons. First, there is a wide range of estimates of $\alpha$. According to Petrongolo and Pissarides (2001), estimates of $\alpha$ that are obtained using a variety of methods and data range between 0.12 and $0.81 .^{9}$ Second, $\alpha$ is estimated for a model without a search intensity decision. Considering that search intensity is not captured in estimating $\alpha, \alpha$ in the current model with a search intensity decision should be higher than empirical estimates, but it is not clear by how much. The weekly separation rate in the steady state, $\bar{\lambda}$, is set at 0.0028 . According to the CPS, this is the average weekly transition probability from employment to unemployment during 2005-2007. $\kappa$ is calibrated to be $\$ 443$, which is 0.584 of average weekly labor productivity. The ratio (0.584) is computed by Hagedorn and Manovskii (2008) by taking in account both the flow costs of capital and labor associated with posting a vacancy.

\subsection{Financial Market}

The borrowing limit $\underline{k}$ is set at -1000 . Together with the discount factor $\beta$, the model with $\underline{k}=-1000$ generates median asset holdings of $\$ 2500$, which is close to median liquid asset holdings of $\$ 2600$ reported by Chetty (2008). The level of the borrowing constraint is also close to the median non-housing debt among the unemployed in the 2005 PSID. However, arguments

\footnotetext{
8 The calibration implicitly assumes that the real wage is moderately sticky $\left(\epsilon_{w}=0.449\right)$, and the large share of the surplus is taken by the worker $(\bar{w}=0.97)$. This is achieved in Hagedorn and Manovskii (2008) by setting the flow utility of unemployment close to that of employment, and allowing high bargaining power for the firm in the generalized Nash bargaining. The assumption of a high value for non-monetary benefits of unemployment (see Section 4.5) is consistent with this interpretation.

9 See Table 3 of Petrongolo and Pissarides (2001).
} 
can be made that the borrowing constraint might be too lax or too strict. The model implies that newly unemployed workers have more assets in median $(\$ 2600)$ than in the data reported by Gruber (2001) (\$1500). On the other hand, Bils et al. (2011) set the borrowing constraint to be equivalent to labor income of six months. Since the level of $\underline{k}$ is crucial in determining the liquidity effect to the search intensity decision (Chetty (2008)), I will conduct a sensitivity analysis with respect to $\underline{k}$.

\subsection{Unemployment Insurance Program}

In calibrating the level of UI benefits in the model, I consider both the monetary UI benefits in the data and non-monetary benefits of unemployment. The former is characterized by the replacement rate $\rho_{b}$, while the latter is characterized by the replacement rate $\rho_{\ell}$. The level of UI benefits in the model, $b$, is set such that $b$ is the fraction $\rho_{b}+\rho_{\ell}$ of the average labor income in the steady state. As for the former, the mean replacement rate for the UI benefits across states, computed by Gruber (1998), is $0.435 .^{10}$ As for the latter, I set the non-monetary benefits of unemployment to be equivalent to the replacement rate of 0.3 . In sum, the amount of the UI benefits in the model is calibrated to be $0.435+0.3=0.735$ of the average labor income (weekly value of $b=541$ ). The total replacement rate of 0.735 is very close to the value calibrated by Costain and Reiter (2006) to replicate the volatility of unemployment and vacancies (0.745). Notice that the resulting amount of UI benefits in the model is close to the average wage, which is consistent with the calibration of Hagedorn and Manovskii (2008). Bils et al. (2011) employ a similar calibration strategy. I will conduct a sensitivity analysis of the main results with respect to the choice of $\rho_{\ell}$ in Section 8.

In pinning down the amount of non-UI benefits in the model, $q$, I combine the average benefits under the food stamp program (Supplemental Nutrition Assistance Program) and the nonmonetary benefits of unemployment. According to the U.S. Department of Health and Human Services (2008), the average monthly benefit per person under the food stamp program was $\$ 92.6$ in 2005, and the average number of family members was 2.3. Therefore, the average weekly benefit per family in 2005 was $\$ 50$ dollars. I also add the same non-monetary benefits of unemployment ( $\rho_{\ell}=0.3$ of the average labor productivity) to the amount of non-UI benefits. This procedure yields the amount of non-UI unemployment benefits of $q=271$.

In the initial steady state, there is no UI benefit extension. Therefore, $x=0$ for all workers. $B(x=0,1)$ is set at 26 weeks, which is the duration of regular UI benefits for a majority of states.

The probability of an ineligible employed worker becoming eligible for UI benefits $\left(\pi_{0,1}^{a}\right)$ is calibrated to match the average proportion of unemployed workers who are receiving UI benefits. Those receiving UI benefits are those who are eligible for UI benefits and have not exhausted the benefits yet. Historically, the proportion of unemployed workers receiving UI benefits fluctuates between 30 percent to 45 percent, and it is strongly countercyclical. The cyclicality is due to the cyclicality of the proportion of firings, which itself is countercyclical, and the extensions of UI benefits, which are made available during severe recessions. In the recent downturn, the proportion of recipients of UI benefits among all unemployed workers increases dramatically,

\footnotetext{
${ }^{10}$ See Table A1 of Gruber (1998). I take a simple average of the replacement rates across all states. The median
} ratio is 0.422 . 
Table 3: Extensions of Unemployment Insurance Benefits in the Model

\begin{tabular}{rrcl}
\hline No $(j)$ & Period $\left(\widetilde{\tau}_{j}\right)$ & Year/Month/Week & Description \\
\hline 0 & 1 & $2007 /$ Dec/5th & Initial state. No extension. \\
1 & 27 & $2008 /$ June/5th & Tier-1 is introduced. \\
2 & 48 & $2008 /$ Nov/4th & Tier-2 is introduced. \\
3 & 60 & $2009 /$ Feb/3rd & Tier-3 is introduced. \\
4 & 74 & $2009 /$ May/4th & Tier-4 is introduced. \\
5 & 98 & $2009 /$ Nov/2nd & Tier-5 is introduced. \\
6 & 112 & $2010 /$ Feb/3rd & Tiers 1-5 UI benefits extended (+1 Tier). \\
7 & 126 & $2010 /$ May/4th & Tiers 1-5 UI benefits extended ( +1 Tier $).$ \\
8 & 140 & $2010 /$ Aug/5th & Tiers 1-5 UI benefits extended ( +1 Tier $).$ \\
9 & 154 & $2010 /$ Dec/1st & Tiers 1-5 UI benefits extended ( +3 Tiers $).$ \\
\hline
\end{tabular}

from around 36 percent in 2005-2007 to 66 percent in 2008-2009, with the highest at about 70 percent. The question of which number should be used as a calibration target is important for the main question of the paper because the proportion directly affects how many workers are affected by changes in the duration and level of UI benefits. Since I am interested in measuring the effect of UI benefit extensions on the unemployment rate during the recent downturn, and there is no endogenous mechanism in the model to generate the increase in the proportion of UIeligible unemployed during downturns except for that due to extensions, I calibrate $\pi_{0,1}^{a}$ such that approximately 70 percent of unemployed workers receive UI benefits when the proportion is at its highest along the baseline transition path. ${ }^{11}$ The calibration strategy generates $\pi_{0,1}^{a}=0.0050$ at a weekly frequency.

\subsection{UI Benefit Extensions}

The UI benefit extensions in the model are carefully designed to mimic the ongoing extensions of UI benefits, which are described in detail in Section 2. Specifically, as in the actual UI extensions, I assume five tiers of extended UI benefits, in addition to the regular UI benefits (labeled Tier 0 ). Tier 0 (regular UI) is available for all workers and provides up to 26 weeks of benefits. This is the only tier available in the initial steady state. Tiers 1 to 4 correspond to Tiers 1 to 4 of the EUC08. Tier 5 in the model corresponds to the EB program, which was made available to most states during the recent downturn and can be used when an unemployed worker exhausts all the benefits under the EUC08. After averaging the duration of Tier 4 and Tier 5 in the model, the five extra tiers provide unemployed workers an additional 20, 14, 13, 13, and 13 weeks of UI benefits, respectively. In total, a worker who is eligible for up to Tier 5 benefits can receive 99 weeks of UI benefits, like workers who are currently unemployed in the U.S. economy.

Extensions of UI benefits in the model are intended to capture the key characteristics of EUC08 and its subsequent expansions and extensions in a stylized manner. Table 3 summarizes the UI benefit extensions in the model. There are nine extensions in the model in total, as in

\footnotetext{
${ }^{11}$ This is not an easy calibration because I need to implement the transition analysis with different values of $\pi_{0,1}^{a}$ to find out the value of $\pi_{0,1}^{a}$ that achieves the calibration target.
} 
the U.S. economy so far. Each of the first five extensions introduces an additional tier, one by one. For example, when Tier 2 is introduced in period 48, all the workers who are eligible for (and most likely receiving) Tier 1 benefits become eligible for Tier-2 benefits as well. Meanwhile, workers who are eligible only for Tier-0 (regular) benefits become eligible for Tier-1 benefits. Workers who are employed at the time of the extension do not become eligible for any additional benefits; when they become unemployed, they are eligible only for the Tier-0 (regular) benefits. Similar things take place until the fifth extension. The dates of the first five extensions roughly correspond to the dates of the original EUC08, its expansions, and the dates when the two levels of the EBs are activated. I also assume that each extension is announced 4 weeks prior to its implementation. I will investigate the importance of the announcement effect by implementing an alternative scenario in which UI benefit extensions are not announced in advance.

The remaining four (6th to 9th) extensions extend only the existing additional UI benefits. These correspond to the last four extensions in the U.S., which also extended the existing additional UI benefits without adding new tiers. Although the length of intervals between each extension in the U.S. economy was not uniform, I assume that all extensions in the model take place with the uniform interval of 14 weeks. The last extension in the model, which took place in December 2010, corresponds to the most recent extension implemented in December 2010. In terms of the length of extensions, I assume that the 6th to 8th extensions add one more tier to all unemployed workers, while the last (9th) extension gives three additional tiers to all unemployed workers. As I discussed in Section 2, the 6th to 9th extensions pushed back the deadline for applying for a new tier by 11.0 weeks on average, while each of the extensions added 14.6 weeks of additional UI benefits on average. Therefore, it is reasonable to assume that each of the 6th to 8th extensions allow unemployed workers to apply for one additional tier beyond what they are already entitled to. As for the last (9th) extension, the deadline for applying for a new tier was pushed back substantially, for 55 weeks. Since 55 weeks roughly corresponds to three extra tiers, I assume that the last extension in the model entitles unemployed workers to three additional tiers. As with the case of the first five extensions, I assume that each of the extensions is announced 4 weeks before its implementation.

\subsection{Transition Path}

In the transition analysis, the separation rate, $\lambda_{t}$, and aggregate productivity, $z_{t}$, change over time in addition to UI benefit extensions. Two remarks are worth making. First, the path of both the separation rate and aggregate productivity is revealed at the beginning of the transition (period 1). In other words, it is a perfect foresight equilibrium with respect to the separation rate and aggregate productivity. Although it is more reasonable that the severity of the downturn was not perfectly predicted in December 2007, it is computationally difficult to assume that the recession was gradually revealed, in addition to multiple policy changes. As you will see in Section 7.1, the model replicates some aspects of the data better if the severity of the recession is gradually revealed. The findings of the paper are naturally affected by this assumption. However, for the main focus of the paper, which is the contribution of the UI benefit extensions on the unemployment rate, the perfect foresight assumption might not be crucial as the severity of the recession was no longer a surprise when most of the extensions were introduced in 2009 and 2010. Second, although the separation rate shock and the aggregate productivity shock are two separate 


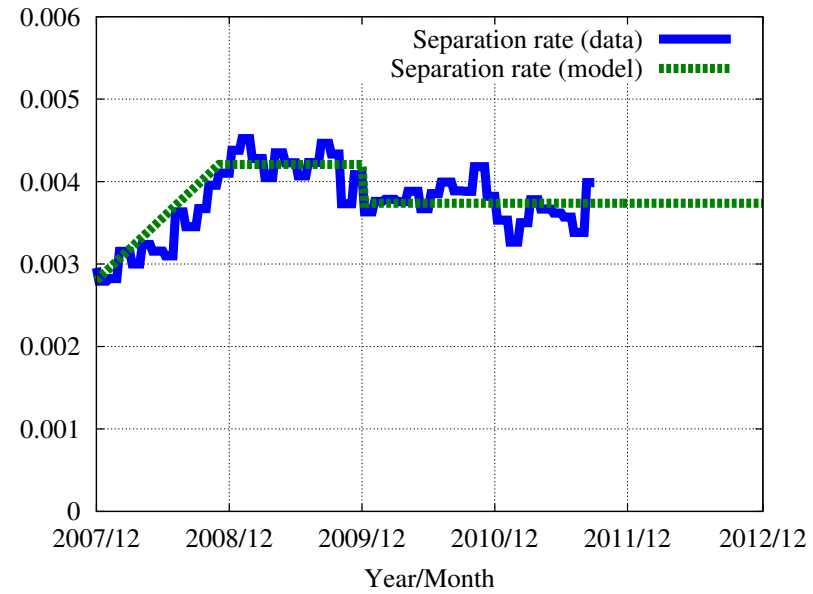

Figure 1: Separation Rate.

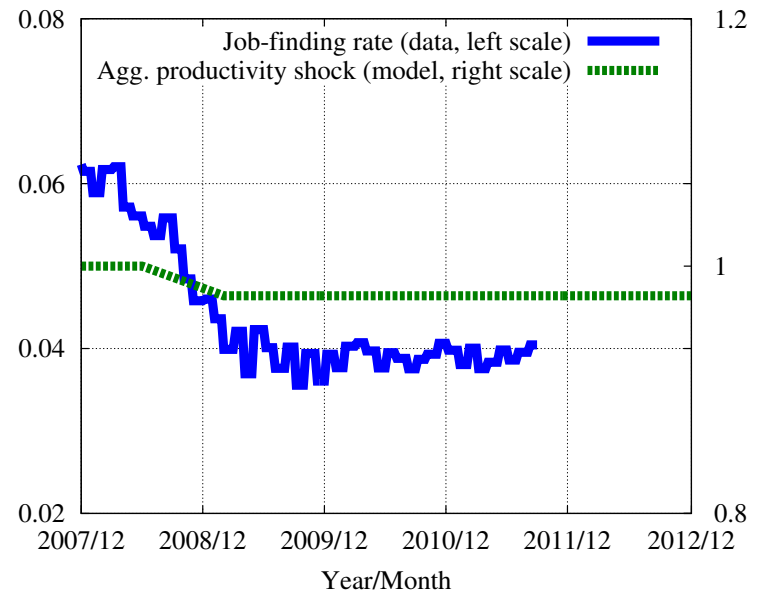

Figure 2: Job-Finding Rate.

shocks in the model, the distinction between the two shocks is technical, since most likely the rising separation was also induced by the same shock that lowered aggregate productivity; the two time-varying parameters together represent the severe economic downturn. ${ }^{12}$

Figure 1 compares the transition rate from employment to unemployment (the separation rate) computed using the CPS, and the smoothed version, which is used as a model input. From the end of 2007 until the third quarter of 2011, when the data are available, the time-varying separation rate is calibrated using the observed separation rate. One can see that the separation rate increased sharply from the end of 2007 to the end of 2008 and that it stayed high until 2011. The input used for the model captures the trend during 2007-2011. Moreover, the separation rate is assumed to stay at the same level until the end of 2012, gradually coming down to the steady-state level by the end of 2014 and remaining at the steady-state level after that in the model.

The transition rate from unemployment to employment (the job-finding rate) during 2007 to 2011, calculated from the CPS, is shown in Figure 2. The job-finding rate dropped sharply from early 2008 to early 2009 and has remained at a low level since then. Notice that there is no straightforward conversion between the job-finding rate and aggregate productivity, which is the input for the model, because the job-finding rate is determined not only by aggregate productivity, but also by the search effort and the number of vacancies posted, both of which are endogenously determined. In order to create the sequence of aggregate productivity used as an input for the transition analysis, I assume that aggregate productivity drops from the end of 2007 until early 2009 from the steady-state level of 1, remains at the low level until the end of 2012, and gradually recovers to the steady-state level until the end of 2014, and then remains at the steady-state level after that. The low level of aggregate productivity is calibrated such that, in the baseline transition analysis, the unemployment rate goes up to around 10 percent in late 2009, which is the highest level observed during the recent downturn. In the baseline transition analysis, it turns out that, with a 1.1 percent drop in aggregate productivity (from 1.00 to 0.989 ),

\footnotetext{
${ }^{12}$ It is straightforward to extend the current environment so that the rising number of separations is also endogenously generated by lower aggregate productivity, which lowers the job-finding rate.
} 
the model can generate a rise in the unemployment rate as large as that observed in the data. The size of the decline in aggregate productivity is significantly smaller than the size of the drop in the job-finding rate for two reasons. First, the other inputs - higher separation rates and UI benefit extensions - already contribute to a large increase in the unemployment rate. Second, as in Hagedorn and Manovskii (2008), a small change in aggregate productivity is amplified to have a large effect on unemployment.

\section{Computation}

The model does not have an analytical solution and thus is solved numerically. While an equilibrium of a heterogeneous-agent model with a deterministic transition has been solved, for example, by Conesa and Krueger (1999), the innovation of the current paper is that there are multiple policy changes (actually nine of them) along the deterministic transition path, and each policy change is announced in advance. I will describe the details of the computation, including how to deal with these novel features, in the Computational Appendix.

\section{Results: Steady State}

\subsection{Properties of the Initial Steady State}

In this section, I first describe the properties of the initial steady-state economy and then investigate the effect of changes in the UI policy using steady-state comparisons. Table 4 summarizes the results. Let's start from the first and second columns, which show the data and the properties of the calibrated initial steady-state economy, respectively. The unemployment rate is 4.77 percent in the model, which is about the average during 2005-2007. Among unemployed workers, 3.2 percent are eligible to receive regular UI benefits (up to 26 weeks), while 1.6 percent are ineligible. Among the eligible unemployed workers, 2.4 percent are receiving the UI benefits, and 0.8 percent have already exhausted the regular UI benefits. The proportion of unemployed workers receiving UI benefits over the total number of unemployed workers is 51 percent. As discussed in Section 4.5, the proportion is higher than the average during 2005-2007 (36 percent), but it is necessary to replicate that the proportion rises to 70 percent during the downturn in the transition simulation. Although policy experiments based on the steady-state comparisons (Section 6.2) are used to calibrate the search elasticity parameter, $\phi$, having a lower proportion of UI recipients among the unemployed in the baseline steady state is not a serious problem, because $\phi$ is calibrated such that the model's responses of the average duration of unemployment among the UI-eligible to changes in the duration or amount of UI benefits are within the range of empirical estimates. The mean unemployment duration of all unemployed workers is 18.2 weeks. It is slightly longer than the average during 2005-2007 in the data (17.4 weeks). The average time spent on search per day is calibrated to be 32 minutes. The weekly job-finding and separation rates are calibrated to be 5.59 percent and 0.28 percent, respectively. The median asset holding is $\$ 2500$ in the model. The mean labor income of employed workers is $\$ 793$.

Since most of the statistics shown in Table 2 are targeted for calibration, they cannot be used to judge the success of the model. Instead, I argue that the model replicates reasonably well how the exit rate (transition probability from unemployment to employment) and the time spent for search activity change over the unemployment spell. As for the empirical exit rate profile, Fujita (2010b) shows that it declines quickly for the first ten weeks and remains low except for the 
Table 4: Steady-State Effect of Changes in Unemployment Insurance Policy

\begin{tabular}{|c|c|c|c|c|c|c|}
\hline Economy & Data & Base & $+10 \%$ & +20 weeks & +73 weeks & $+\infty$ weeks \\
\hline UI replacement rate & 0.4350 & 0.4350 & 0.5350 & 0.4350 & 0.4350 & 0.4350 \\
\hline Duration of UI benefits ${ }^{1}$ & 26 & 26 & 26 & 46 & 99 & $\infty$ \\
\hline Unemployment rate (U) & 0.0477 & 0.0477 & 0.0489 & 0.0520 & 0.0627 & 0.0770 \\
\hline UI-eligible & & 0.0319 & 0.0332 & 0.0364 & 0.0473 & 0.0618 \\
\hline Receiving benefits & 0.0173 & 0.0242 & 0.0248 & 0.0324 & 0.0462 & 0.0618 \\
\hline$(\%$ of $U)$ & 36.17 & 50.70 & 50.64 & 62.37 & 73.63 & 80.25 \\
\hline Exhausted benefits & & 0.0077 & 0.0084 & 0.0040 & 0.0011 & - \\
\hline UI-ineligible & & 0.0158 & 0.0157 & 0.0156 & 0.0154 & 0.0152 \\
\hline Mean duration $^{1}$ & 17.40 & 18.21 & 18.55 & 20.02 & 26.44 & 37.46 \\
\hline Among UI-eligible & & 18.68 & 19.18 & 21.24 & 29.47 & 42.45 \\
\hline Among UI-ineligible & & 17.24 & 17.21 & 17.16 & 17.15 & 17.16 \\
\hline Aggregate search effort ${ }^{2}$ & & 1.8123 & 1.8109 & 1.8062 & 1.7884 & 1.7623 \\
\hline Average search effort ${ }^{3}$ & 32.0 & 32.0 & 31.1 & 29.2 & 24.0 & 19.2 \\
\hline Vacancies $^{2}$ & & 43.027 & 42.925 & 42.715 & 42.070 & 41.355 \\
\hline Market tightness $^{4}$ & & 1.0000 & 0.9984 & 0.9961 & 0.9909 & 0.9885 \\
\hline Job-finding rate & 0.0559 & 0.0559 & 0.0545 & 0.0511 & 0.0419 & 0.0336 \\
\hline Separation rate & 0.0028 & 0.0028 & 0.0028 & 0.0028 & 0.0028 & 0.0028 \\
\hline Median asset ${ }^{5}$ & 2600 & 2500 & 1800 & 1300 & 900 & 1000 \\
\hline Mean labor income ${ }^{5}$ & 793 & 793 & 792 & 791 & 788 & 787 \\
\hline Prop of low skilled & & 0.2025 & 0.2061 & 0.2128 & 0.2311 & 0.2471 \\
\hline Prop of medium skilled & & 0.2162 & 0.2168 & 0.2168 & 0.2163 & 0.2137 \\
\hline Prop of high skilled & & 0.5813 & 0.5771 & 0.5703 & 0.5526 & 0.5392 \\
\hline
\end{tabular}

1 In weeks.

${ }^{2}$ Multiplied by 1000.

${ }^{3}$ In minutes per day.

${ }^{4}$ Normalized such that it is one in the baseline model.

${ }^{5}$ In 2005 U.S. dollars.

temporary spike around the 26 th week. ${ }^{13}$ Figure 3 exhibits the exit rate profile generated by the model. The model successfully captures the qualitative features of the empirical exit rate profile, although the levels of the exit rate at the beginning of an unemployment spell and the spike at

\footnotetext{
$\overline{13}$ Notice that there is a difference between the exit rate from unemployment to employment, and the unconditional exit rate, which includes the exit from the labor force. The shape of the exit rate profile is similar, but the spike at around the 26th week is more pronounced for the latter, as seen in Meyer (1990), since many workers exit from unemployment to out-of-the-labor-force when the regular benefits expire after the 26th week.
} 


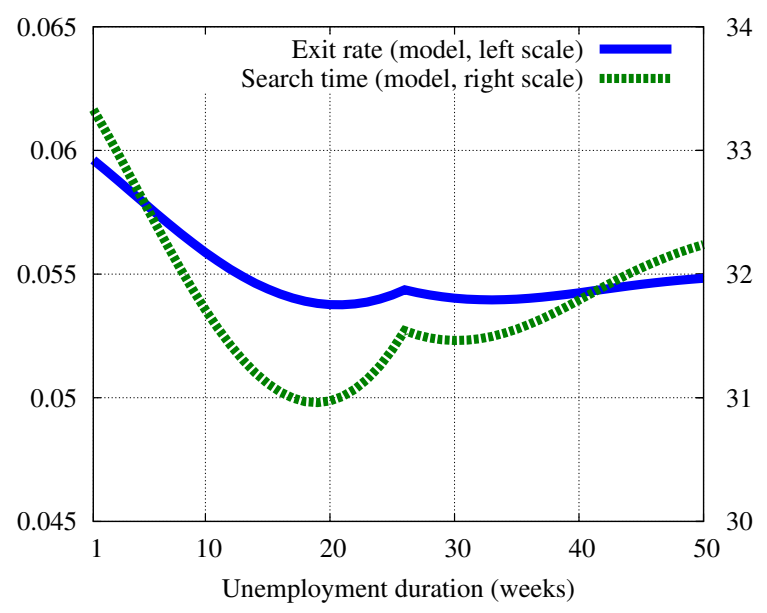

Figure 3: Exit Rate and Search Time: All Unemployed Workers.

around the 26th week is much less pronounced than the levels observed in the data. In order for the model to replicate both qualitatively and quantitatively the exit rate profile, more features, such as richer heterogeneity, temporary layoffs, stock-flow matching, and learning, might be needed. Moreover, the empirical spike at around the 26th week might be partly due to rounding up when reporting. The rounding-up hypothesis is supported by the fact that the exit rate also temporarily rises at around one year.

As for the search time profile, Krueger and Mueller (2010) and Krueger and Mueller (forthcoming) provide valuable empirical evidence, but it is not easy to reconcile the findings of the two studies. Let's start with the former. The calibrated model replicates the data provided by Krueger and Mueller (2010) in the sense that the search time declines to around the 20th week, goes up sharply around the 26th week, and declines after the 26th week. Krueger and Mueller (2010) report that the time for job search is around 50 minutes in the first 14 weeks of unemployment and declines to about 30 minutes before it rises to 70 minutes at the 26 th week. The search time declines again after the 26th week. However, quantitatively the changes in the model over the unemployment spell are too small compared with the data. On the other hand, in their recent paper, Krueger and Mueller (forthcoming) argue that the time for job search declines for all cohorts regardless of the duration of unemployment, according to their surveys conducted in the fall of 2009. ${ }^{14}$ This is inconsistent with the findings of Krueger and Mueller (2010), and it is hard to reconcile this search time profile with the exit rate profile that I discussed above. However, their interpretation is based on the assumption that the time effect (the recession is discouraging all the unemployed to reduce search time) is small, while it is difficult to identify the time effect and the unemployment duration effect. If we take the alternative interpretation that the time effect is significant, a different picture emerges; their figures suggest that the time for job search is relatively stable, or even increasing during the unemployment spell, but the time effect is pushing the time for job search down for all cohorts during the sample period. The search time profile shown in Figure 3, which is fairly stable over the unemployment spell, is

\footnotetext{
14 See Figure 3.1 of their paper.
} 


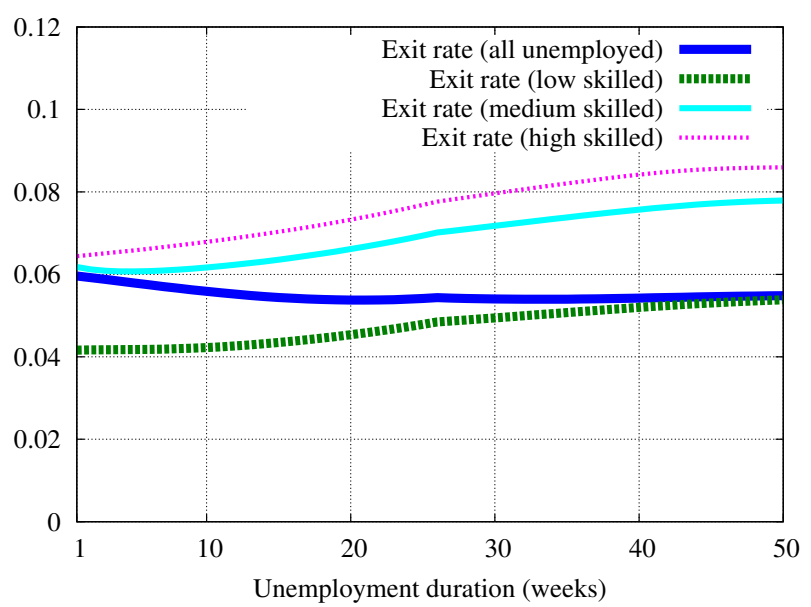

(a) Skill levels

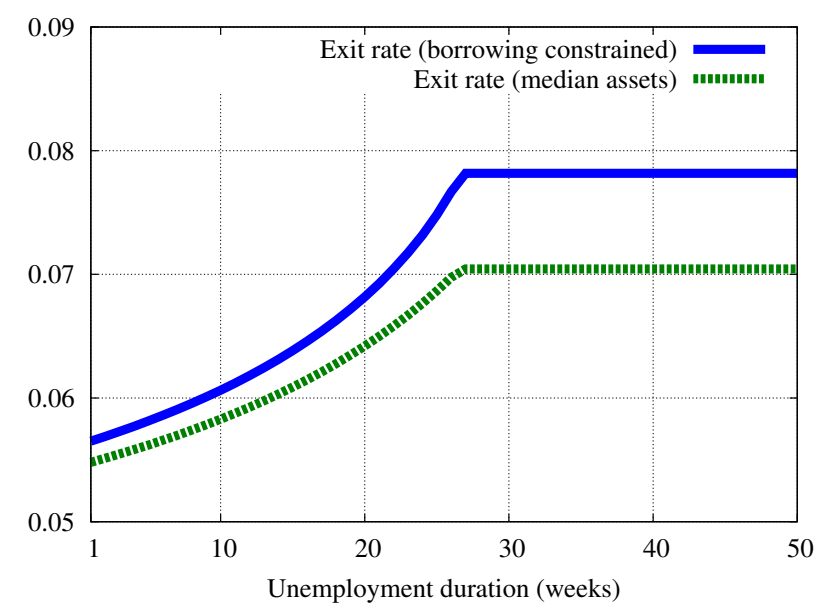

(b) Asset holding

Figure 4: Weekly Exit Rate: Decomposition.

reasonably consistent with such interpretation.

Notice that it is not easy for a model of job search to generate an exit rate or profile of search time that is not monotonically increasing. Conditional on the type of worker, the incentive for search keeps increasing in the unemployment spell as the remaining duration of UI benefits keeps shrinking and the assets keeping depleting. The reason why the profiles of the exit rate and the time for job search in the model are not monotonically increasing is the composition effect. Panel (a) of Figure 4 exhibits the exit rate for each skill group as well as the exit rate of all unemployed workers. Although the exit rate function is upward sloping conditional on the skill type, as unemployed workers experience skill depreciation, the exit rate function keeps shifting down. Notice that, in Figure 4 (a), the overall exit rate is close to the exit rate among the medium skilled for short unemployment spells, while the exit rate is mainly determined by that of the low skilled for long unemployment spells. This is because the average skill level depreciates from medium skill to low skill during an unemployment spell.

Panel (b) of Figure 4 shows how exit rates are affected by asset holdings. When there is a borrowing constraint, unemployed workers are more desperate in searching if they are close to the constraint, and thus their consumption is constrained by it. Chetty (2008) emphasizes this liquidity effect by distinguishing it from the standard moral hazard effect. In Figure 4 (b), the line below is the exit rate for medium-skilled UI-eligible unemployed workers with median asset holdings, and the line above is for the same type of unemployed workers at the borrowing constraint. When the level of asset holdings is at the borrowing constraint, their consumption is constrained by current income. As you can see in Figure 4 (b), the search intensity, and thus the exit rate, are higher when asset holdings are lower. Conditional on the skill type, the overall exit rate goes up with unemployment duration partly because unemployed workers become more desperate as they approach the maximum duration of UI benefits and partly because they exhaust their assets. Finally, this property implies that the slope of the exit rate is steeper if the borrowing constraint is tighter. If the model is calibrated so that the unemployed are more 
likely to be borrowing constrained, holding all else fixed, the average duration of unemployment in the model will be shorter (and closer to the data), but the slope of both the exit rate and the search time will be steeper during the unemployment spell, which could make them inconsistent with the data.

\subsection{Policy Experiments: Changes in UI Benefit Policy}

The third to sixth columns of Table 4 summarize the effects of changing the UI benefit policy in a variety of ways. The third column of Table 4 shows the effect of increasing the replacement rate of monetary UI benefits by 10 percentage points while keeping the duration of UI benefits at 26 weeks. I use 10 percentage points because various empirical estimates are available for the response of the average unemployment duration to a 10-percentage-point increase in the replacement rate of UI benefits. Existing estimates are in the range of a 0.5-1.5 week increase in the average duration among the UI-eligible unemployed. All of the available estimates are obtained by estimating the hazard function out of unemployment, but the difference arises because of the data, estimation methodology, and the sample period. Hamermesh (1977) concludes that "the best estimate - if one chooses a single figure - is that a 10-percentage-point increase in the gross replacement rate leads to an increase in the duration of insured unemployment of about half a week when labor markets are tight." Moffitt and Nicholson (1982) find that a 10-percentagepoint increase in the replacement rate is associated with an increase in unemployment duration of about 0.8-1.0 week. Meyer (1990) estimates the effect to be an increase of 1.0-1.5 weeks of average unemployment duration. Moffitt (1985) obtains the effect to be a 0.5 week increase in potential duration.

In the baseline model, the mean duration of unemployment among UI-eligible unemployed workers increases by about 0.5 week, from 18.7 to 19.2 weeks. The response of the average duration is at the lower bound of the range of empirical estimates of 0.5-1.5 weeks. Since the model is calibrated to generate the lower bound of the range of the estimated response, the calibration can be considered conservative. The longer unemployment duration is caused by a disincentive effect; more generous UI benefits discourage the search efforts of workers who are eligible for UI benefits. Since UI-ineligible workers are not directly affected by the policy change, the mean duration of unemployment of UI-ineligible workers does not change. The unemployment rate increases from the baseline rate of 4.77 percent to 4.89 percent. While the number of unemployed workers increases, the average search effort declines (from 32 to 31 minutes per day), resulting in a slight decline in the aggregate search effort (0.08 percent). Since the decline in the aggregate search effort is relatively small, the decline in vacancies is also relatively small at 0.24 percent. As a result, labor market tightness declines by 0.16 percent. More generous UI benefits also discourage precautionary savings. Median asset holdings drop from $\$ 2500$ to $\$ 1800$. Although I do not consider the general equilibrium effect from declining aggregate savings, this could have a negative effect on output, in addition to the one caused by a lower employment rate.

The fourth to sixth columns show the effect of increased duration of UI benefits, by 20, 73, and infinite weeks, respectively. The 73-week increase is chosen because the addition of 73 weeks makes the total duration 99 weeks, which is the longest duration currently available in the U.S., and how the economy is affected by the currently implemented extensions is the main 
question of this paper. This experiment is also intended to show that a steady-state analysis can be misleading because the extensions that are currently in place are very different from the steady state where all workers expect 99 weeks of UI benefits when they become unemployed, although the potential maximum duration of UI benefits is currently 99 weeks. The last column is associated with an economy with permanent UI benefits.

On the empirical side, existing estimates are in the range of a 0.08-0.2 week increase in average unemployment duration in response to a 1-week increase in the duration of UI benefits. Moffitt (1985) estimates the effect of a 1-week extension of UI benefits to be about a 0.15 week increase in the average unemployment spell of UI recipients. Moffitt and Nicholson (1982) estimate the effect to be 0.1 week. The estimate obtained by Katz and Meyer (1990) is a 0.16-0.20 week increase in the average duration of unemployment spells by UI recipients. More recently, Card and Levine (2000) obtain the smallest estimate. They use the UI benefit extension of 13 weeks in New Jersey that lasted for six months and estimate the effect of a 1-week increase in UI benefits on the average unemployment duration to be 0.08 week.

To compare the empirical estimates with the output of the model, let's look at the 20-week increase. The average duration of unemployment among UI-eligible unemployed workers increases by about 2.5 weeks, from 18.7 to 21.2 weeks. This means that a 1 -week increase of UI benefit duration is associated with an increase in the average UI-insured duration of 0.13 weeks. The response of the average duration is approximately in the middle of the range of empirical estimates of $0.08-0.2$. Although the response of the calibrated baseline model to a 10-percentage-point increase in the replacement rate of UI benefits is at the lower bound of the available empirical estimates, I put more emphasis on matching the model's response to an increase in the duration of UI benefits, because the main focus of the paper is the ongoing UI benefit extensions. The unemployment rate goes up to 5.2 percent (0.4-percentage-point increase). The labor market tightness declines by 0.4 percent. The job-finding rate declines from 5.6 percent per week to 5.1 percent. Median asset holdings decline substantially from $\$ 2500$ to $\$ 1300$, as the precautionary saving motive is weakened by the longer availability of UI benefits. A longer duration of unemployment shifts the composition of skilled and unskilled workers; as the more generous UI benefit duration discourages the search effort and induces unemployed workers to remain unemployed longer, more workers lose their skills during unemployment spells. As a result, the proportion of high-skilled workers in the economy drops from 58 percent in the initial steady state to 57 percent, which lowers the average wage of workers from $\$ 793$ to $\$ 791$. When the UI benefit duration is further increased to 99 weeks, and then infinite weeks, the effect observed in the 20 -week extension is further strengthened. In the steady-state comparison, an increase in the UI benefit duration from 26 to 99 weeks increases the unemployment rate by 1.5 percentage points, from 4.8 percent to 6.3 percent. However, as I will show in the next section, this is misleading as the effect of the current UI extensions on the unemployment rate because of the gradual and temporary nature of the ongoing extensions of UI benefits. In the limit case in which UI benefits are available permanently, the unemployment rate soars to 7.7 percent. 


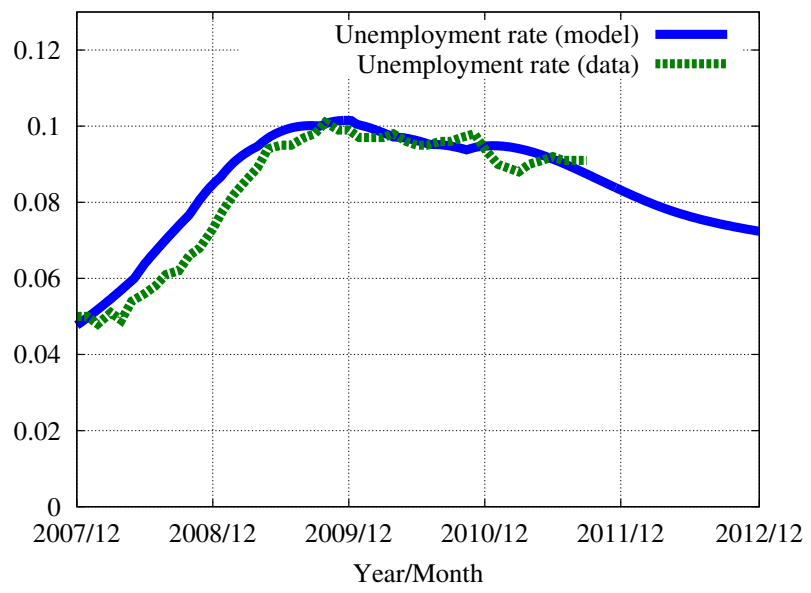

(a) Unemployment rate

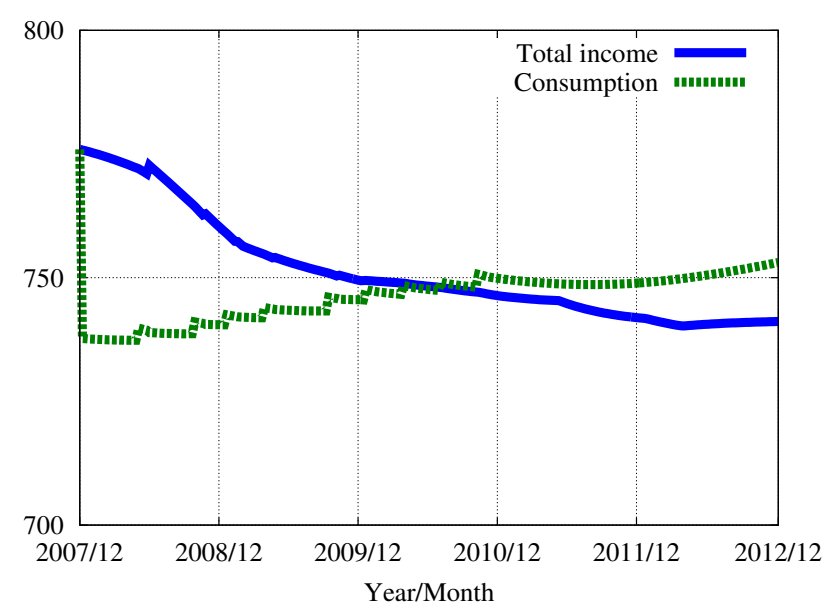

(c) Income and consumption

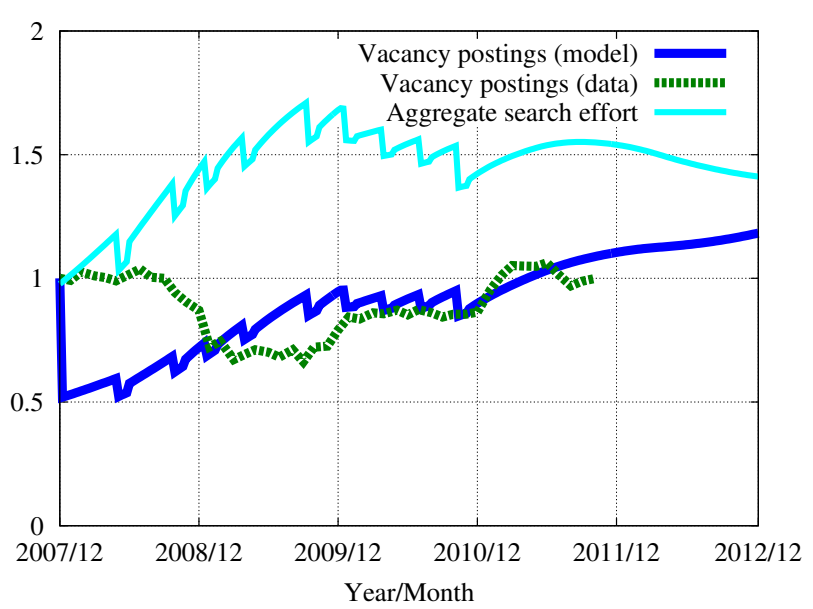

(b) Search effort and vacancies $(2007 / 12=1)$

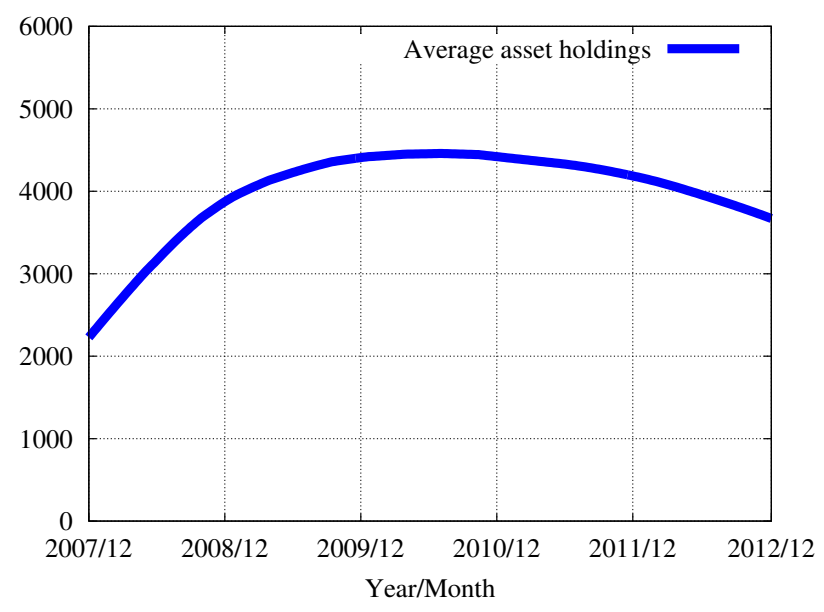

(d) Average asset holdings

Figure 5: Transition Dynamics (2007/12-2012/12).

\section{Results: Transition Dynamics}

\subsection{Transition Dynamics of the Baseline Economy}

Figure 5 summarizes the baseline equilibrium transition path generated by the model between December 2007 and December 2012. Panel (a) of Figure 5 compares the unemployment rate in the data and the one generated by the model. They are close to each other; both increase sharply between the end of 2007 and 2009 and have remained high at slightly below 10 percent since then. The closeness is not a result; the aggregate productivity is calibrated to achieve it. As there are no more UI benefit extensions, and both the aggregate productivity and separation rate are assumed to gradually revert to their respective steady-state levels, the unemployment rate in the model is predicted to gradually go back to its steady-state level of 4.77 percent. The unemployment rate of the model increases faster than in the data in 2008, because the future 
path of aggregate productivity is completely revealed at the beginning of the transition; firms in the model reduce the number of vacancy postings faster than in the data as the firms know that productivity will be low for a while. If the future path of aggregate productivity is revealed gradually, the unemployment rate in the model rises more slowly and thus fits the empirical counterpart better.

Panel (b) shows the number of vacancies posted in the model and in the data, and the aggregate search effort. The number of vacancies in the data is the Help-Wanted OnLine compiled by the Conference Board. All data series are normalized such that the value is one in December 2007. In the model, the number of vacancies dropped significantly at the beginning of the transition, when the future path of aggregate productivity is revealed. Since then, the number of vacancies have gradually recovered. Surprisingly, the model is successful in replicating the path of the number of vacancies in the data, except for the sudden drop at the beginning. The number of vacancies in the model tracks the number of vacancies in the data more closely if the information about future aggregate productivity is gradually revealed, which would make the drop in vacancies at the beginning of the transition gradual. Both in the data and in the model, although the number of vacancies has been recovering after the initial drop, the unemployment rate has remained high because the successive extensions of UI benefits kept the unemployment rate elevated. The hump shape of the aggregate search effort is less pronounced than the hump shape of the unemployment rate, because the individual search effort is decreasing while the unemployment rate is rising. Finally, notice that the aggregate search effort and the number of vacancies exhibit multiple kinks. Each of the kinks corresponds to an announcement of a new UI benefit extension; each time a new UI benefit extension is announced, the search effort shifts down, due to the (anticipated) negative incentive effect. The number of vacancies drops as well since the expected amount of search effort is downward adjusted when a new UI benefit extension is announced.

Panel (c) of Figure 5 shows the path of average income and consumption. Average income declines gradually as more workers are unemployed and receive unemployment benefits instead of labor income. Moreover, skill depreciation plays a role. The proportion of high-skill workers declines from 58 percent at the end of 2007 to 49 percent at the bottom, while the proportion of low-skill workers increases from 20 percent to 28 percent. As a result, average labor income declines from $\$ 793$ in the initial steady state to $\$ 767$ at its bottom. Not only does skill depreciation reduce the aggregate stock of skills in the economy, but it also reduces the job-finding rate of the unemployed who lose skills and prolongs the period of high unemployment further. Average consumption drops immediately when the recession (future path of the separation rate and aggregate productivity) is revealed, in order to increase precautionary savings. As the economy is approaching the end of the recession, which reduces precautionary savings, and as the unemployment rate recovers, average consumption gradually comes back to the pre-recession level as well. Notice that average consumption ticks up each time a new UI benefit extension is announced, since the expected lifetime income, especially of the unemployed, increases with an extension (UI-benefits are higher than non-UI-benefits).

Panel (d) shows the path of mean asset holdings. Mean asset holdings keep rising after the recession is revealed. Mean asset holdings increase from the initial value of $\$ 2228$ to $\$ 4460$ during 2008-2010 and then gradually revert to the initial steady-state level after 2010. It is an optimal response of precautionary savings to a higher risk of separation and a longer unemployment 


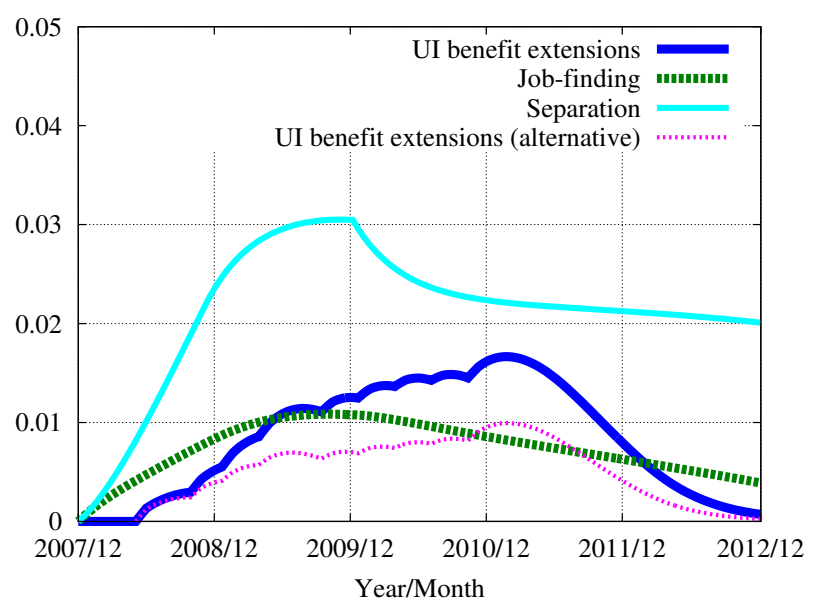

Figure 6: Decomposition of the Unemployment Rate.

spell. It is interesting to note that the saving rate has remained high in the U.S. since the recent downturn started. Increased savings are often attributed to the deleveraging from the state of excess borrowing, but this increase can also be rationalized as the increased precautionary savings in response to a higher labor market risk.

\subsection{Contribution of UI Benefit Extensions on Unemployment}

In order to measure the contribution of UI benefit extensions, the time-varying separation rate, and time-varying aggregate productivity, which affects the job-finding rate, to the unemployment rate, I run two counterfactual experiments. First, I simulate the baseline economy without the UI benefit extensions. The difference in the unemployment rate between the baseline economy and the counterfactual economy without the extensions gives the contribution of UI benefit extensions to the unemployment rate. Next, I further replace time-varying aggregate productivity by its steady-state value and simulate the economy again. The difference in the unemployment rate between the two counterfactuals provides the measure of the contribution of aggregate productivity to the unemployment rate. Finally, if all three elements (the UI benefit extensions, the time-varying separation rate, and time-varying aggregate productivity) are turned off, the unemployment rate will stay at the steady-state level. Therefore, the difference in the unemployment rate between the counterfactual economy with only the time-varying separation rate and the steady-state unemployment rate gives the measure of the contribution of the time-varying separation rate to the unemployment rate. Figure 6 plots the three measures. On average between August 2008, when the unemployment rate in the data reached 9.7 percent, and September 2011, the period for which the latest data are available, the contribution of the nine UI benefit extensions is 1.4 percentage points, or 29 percent of the overall increase in the unemployment rate (4.8 percentage points). The contribution of economic conditions is the remaining part, which is 3.4 percentage points. Among the 3.4 percentage points, 2.5 percentage points (52 percent of the overall increase in the unemployment rate) are attributed to the rising separation rate, while 0.9 percentage point (19 percent) is attributed to the stagnating job-finding rate due to low aggregate productivity. 
What is striking are the changes in the relative contribution of the three elements over the simulation period. The initial increase in the unemployment rate is mainly due to the economic environment, in particular, the rising separation rate, while the UI benefit extensions were yet to be introduced. However, as the UI benefit extensions started being enacted, the contribution of the UI benefit extensions continued to rise. In the first quarter of 2011, the contribution of the UI benefit extensions reached 1.7 percentage points, while the contributions of the separation rate and aggregate productivity were 2.2 and 0.8 percentage points, respectively. The successive renewal of the UI benefit extensions kept the unemployment rate elevated in 2011 even though the number of vacancies posted continued to recover (see Figure 5 (b)), and the separation rate has shifted down since 2010 (see Figure 1).

The effect of the UI benefit extensions to the unemployment rate is significantly affected by the economic condition. This is shown in Figure 6 as "UI benefits extensions (alternative)." In particular, I show the changes in the unemployment rate when only the UI benefit extensions are implemented without changing the separation rate or aggregate productivity from their steadystate levels. The effect of the extensions on the unemployment rate is measured to be smaller than the number computed above. On average between August 2008 and September 2011, the contribution is 0.8 percentage point instead of 1.4 percentage points. The main reason is that a higher separation pushes more workers into unemployment, which makes the effect of discouraged search efforts on the unemployment rate greater.

Finally, remember that the effect of extending the duration of UI benefits up to 99 weeks on the unemployment rate is 1.5 percentage points in the steady-state analysis (Table 4). Although it is close to the contribution of the UI benefit extensions obtained from the baseline transition analysis (1.4 percentage points), it does not mean that the transition analysis is not adding much to the steady-state analysis. First, the comparable number to the steady-state analysis is 0.8 percentage point, which is obtained by just introducing the UI benefit extensions but without introducing the time-varying separation rate and aggregate productivity. The difference implies that the unemployment rate would be 0.6 percentage point higher than it is already if the UI benefit up to 99 weeks is made permanent. In other words, not surprisingly, the steady-state analysis is overstating the effect of the UI benefit extensions by not taking into account the gradual and temporary nature of the extensions. On the other hand, the transition analysis incorporates the recession (time-varying separation rate and aggregate productivity) as well, which ends up making the contribution from the UI benefit extensions to the unemployment rate in the transition analysis close to the one obtained in the steady-state analysis.

\subsection{Policy Experiments: Counterfactual UI Benefit Extensions}

The last UI benefit extension was agreed between the President and Congress in December 2010. This last extension did not increase the maximum duration of UI benefits (which remains at 99 weeks), but it allows those who did not exhaust the maximum duration of benefits and at the same time did not qualify for some of benefits because of the deadline to apply for a higher tier. The focus of the discussion regarding the last extension was mainly its implications

for government finances, especially after the outstanding balance of the government debt soared with the series of fiscal stimuli, and how it helps the long-term unemployed. Although both issues are important, the extension also has a negative effect on the search effort, which is the main 


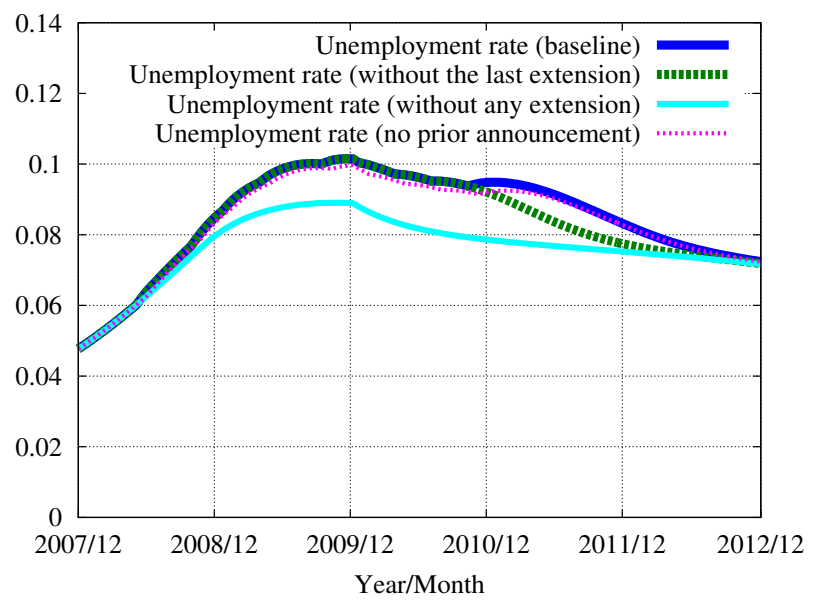

Figure 7: Unemployment: Counterfactual experiments.

focus of the current paper. In trying to quantify the effect, I run a counterfactual experiment in the model economy where the last extension in the model is not implemented. Figure 7 compares the dynamics of the unemployment rate under the baseline transition path, where all nine extensions are implemented, and under the counterfactual transition path, where the last extension (December 2010) is not implemented. As you can see, when labor market conditions improved (by assumption) and the economy reverted to its steady state, the last extension kept the unemployment rate higher during the transition. In other words, the decline in the unemployment rate would have been faster in the counterfactual case without the last extension. The difference in the unemployment rate is 0.6 percentage point on average in 2011 . If a further extension of a similar magnitude is going to be implemented once the current extension expires, a similar effect on the unemployment rate would be expected. Needless to say, in evaluating the last extension, it is important to compare the cost of slower recovery shown here, with the insurance provided to those who are unemployed, and fiscal implications. This is left for future research.

The extreme case in which no UI benefit extension is implemented is also shown in Figure 7. In that scenario, the highest unemployment rate during the recent downturn would have been around 9 percent instead of 10 percent. In 2011, the unemployment rate under the counterfactual scenario would be around 7.7 percent instead of the baseline rate of 9.0 percent, as the contribution of UI benefit extensions to a higher unemployment rate increases.

Finally, how large is the announcement effect? The baseline assumption is that each UI benefit extension is announced 4 weeks before its implementation, which allows potential beneficiaries to start reacting (reducing search time) before the actual implementation of UI benefit extensions. Figure 7 also includes the counterfactual simulation in which there is no prior announcement for all extensions; extensions are perfect surprises for agents in the economy. The difference between the baseline case in which extensions are announced 4 weeks in advance and the counterfactual case without announcements is relatively small; the difference is between 0.1 to 0.3 percentage point in the unemployment rate. 
Table 5: Sensitivity Analysis

\begin{tabular}{|c|c|c|c|c|c|c|}
\hline \multirow[t]{2}{*}{ Economy } & \multicolumn{2}{|c|}{$\Delta$ in unemployment duration ${ }^{1}$} & \multicolumn{4}{|c|}{$\Delta$ in the unemployment rate $^{2}$} \\
\hline & $\begin{array}{l}10 \% \Delta \text { in } \\
\text { rep. rate }\end{array}$ & $\begin{array}{l}1 \text { week } \Delta \text { in } \\
\text { UI duration }\end{array}$ & Total & $\begin{array}{l}\text { UI benefit } \\
\text { extensions }\end{array}$ & $\begin{array}{r}\text { Separation } \\
\text { rate }\end{array}$ & $\begin{array}{r}\text { Aggregate } \\
\text { productivity }\end{array}$ \\
\hline Data & $0.50-1.5$ & $0.08-0.20$ & 4.7 & & & \\
\hline Baseline $^{3}$ & 0.50 & 0.13 & 4.8 & 1.4 & 2.5 & 0.9 \\
\hline$\phi=2.03$ & 0.31 & 0.08 & 4.7 & 0.9 & 2.3 & 1.6 \\
\hline$\phi=1.50$ & 0.37 & 0.10 & 4.8 & 1.1 & 2.3 & 1.4 \\
\hline$\phi=0.50$ & 0.69 & 0.17 & 5.0 & 1.9 & 2.8 & 0.3 \\
\hline$\phi=0.35$ & 0.82 & 0.20 & 5.4 & 2.4 & 3.1 & 0.0 \\
\hline$\sigma=1$ & 0.33 & 0.10 & 4.9 & 1.0 & 2.5 & 1.4 \\
\hline$\alpha=0.50$ & 0.52 & 0.13 & 4.8 & 1.3 & 3.3 & 0.1 \\
\hline$\rho_{\ell}=0$ & 0.76 & 0.20 & 4.9 & 2.1 & 2.6 & 0.1 \\
\hline$\rho_{\ell}=0.15$ & 0.54 & 0.15 & 4.8 & 1.6 & 2.5 & 0.7 \\
\hline$\underline{k}=0$ & 0.66 & 0.16 & 5.0 & 1.7 & 2.4 & 0.9 \\
\hline$\underline{k}=-2000$ & 0.45 & 0.12 & 4.7 & 1.3 & 2.5 & 0.9 \\
\hline $\bar{\omega}=0.95$ & 0.50 & 0.13 & 4.8 & 1.4 & 2.5 & 0.9 \\
\hline$\epsilon_{w}=0$ & 0.50 & 0.13 & 4.9 & 1.4 & 2.5 & 1.0 \\
\hline$\epsilon_{w}=0.9$ & 0.50 & 0.13 & 4.8 & 1.5 & 2.5 & 0.8 \\
\hline
\end{tabular}

${ }^{1}$ Among the UI-eligible unemployed. Steady-state comparison.

${ }^{2}$ Change from December 2007 to the average of September 2009 - September 2011.

3 The calibrated parameter values in the baseline model economy are: $\phi=0.92, \sigma=2, \rho_{\ell}=0.3$, $\underline{k}=-1000, \bar{\omega}=0.97$, and $\epsilon_{w}=0.449$.

\section{Sensitivity Analysis}

I explore the sensitivity of the main results, which is the effect of UI benefit extensions on the unemployment rate, regarding the variety of parameters. Table 5 summarizes the results. The first panel of Table 5 states the data and the baseline results. The second to fourth panels correspond to three sets of sensitivity results. The second panel is associated with the sensitivity with respect to the search elasticity parameter $\phi$. Remember that, in the baseline calibration, $\phi=0.92$ is obtained such that the responses of the average unemployment duration to changes in the amount and the duration of UI benefits in the calibrated model are within the range of available empirical estimates. In investigating the effects of $\phi$, I fix $\phi$ to variety of values, and implement the same experiments as for the baseline model. Let's start from $\phi=1.5$ (the second row in the second panel). $\phi=1.5$, which means a lower elasticity of search intensity than in the baseline, corresponds to a weaker response of the model to changes in the UI benefit policy. The average duration of unemployment increases by 0.37 week in response to a 10-percentagepoint increase in the replacement rate of UI benefits. This is lower than the lower bound of the available empirical estimates (0.50). The average unemployment duration increases by 0.10 
week in response to a 1-week increase in the duration of UI benefits, compared to 0.13 week in thew baseline experiment. Not surprisingly, the contribution of the UI benefit extensions to the unemployment rate is smaller than the baseline results, at 1.1 percentage points. I further lower the search elasticity (increase $\phi$ ) so that the model's response to a 1-week increase in the duration of UI benefits is at the lower bound of the available empirical estimates (0.08). This procedure yields $\phi=2.03$ (top of the second panel). The average unemployment duration increases by 0.31 week when the replacement rate of UI benefits is increased by 10 percentage points, which is further below the lower bound of the available empirical estimates (0.50). The contribution of the UI benefit extensions to the unemployment rate is further reduced, to 0.9 percentage point. Considering that the model's response to steady-state changes in the UI benefit policy are either at the lower bound or below, 0.9 percentage point provides the lower bound of the contribution of the UI benefit extensions on the unemployment rate implied by the model.

In the opposite case where $\phi$ is lower (search elasticity is higher) than in the baseline calibration, the response of the model to changes in the UI benefit policy is stronger. With $\phi=0.5$ (third row in the second panel), the response of the average unemployment duration to a 10percentage-point increase in the replacement rate is 0.69 week. The average duration of unemployment increases by 0.17 week in response to a 1-week increase in the duration of UI benefits. The current UI benefit extensions contribute to a 1.9-percentage-point increase in the unemployment rate, compared to 1.5 percentage points in the baseline experiment. If I further increase the search elasticity (lower $\phi$ ) so that the model's response to a 1-week increase in the duration of UI benefits is at the upper bound of the available empirical estimates, $\phi=0.35$ is obtained. With $\phi=0.35$ (bottom of the second panel), the contribution of the UI benefit extensions to the unemployment rate is 2.4 percentage points. Notice that, the model with $\phi=0.35$ implies a larger increase in the unemployment rate than in the data even though the contribution from the average productivity is calibrated to be zero. Therefore, the 2.4-percentage-point increase in the unemployment rate can be considered the upper bound of the contribution of the UI benefit extensions implied by the model.

The third panel of Table 5 summarizes the sensitivity with respect to other parameters that change the steady state of the model. I fix the search intensity parameter $\phi$ at the baseline value of 0.92, recalibrate the model, and run the same experiments as in the baseline model. First, $\sigma=1$, which implies log utility for consumption, makes the contribution of the UI extensions to the unemployment rate smaller (1.0 percentage point). Not surprisingly, it also implies that the response of the average unemployment duration of the model to a 10-percentage-point increase in the UI replacement rate is too small (0.33) compared with the data. It is easy to see that once $\phi$ is recalibrated as in the baseline model, the contribution of the UI benefits to the unemployment rate will be larger and close to the baseline model. This argument can be applied to all the sensitivity experiments in this group. In other words, the bounds of the main result obtained in the sensitivity analysis with respect to $\phi$ are to a large extent valid even if other parameter values are changed, as long as $\phi$ is recalibrated. Second, the curvature parameter for the matching function $\alpha$ is lowered to 0.5 from the baseline value of 0.72 . As you can see, the contribution of the UI benefit extensions on the unemployment rate does not change significantly (1.3 percentage points), but the composition between the separation rate and aggregate productivity changes; while the rising separation rate contributes to a 2.5 -percentage-point in- 
crease in the unemployment rate in the baseline experiment, the contribution is 3.3 percentage points with $\alpha=0.5$. Next is the sensitivity analysis with respect to the non-monetary benefit of unemployment, $\rho_{\ell}$. It is reduced from the baseline value of $\rho_{\ell}=0.3$ to 0.15 and 0 for sensitivity analysis. $\rho_{\ell}=0.15$ is the intermediate value and corresponds to the calibration of Bils et al. (2011). $\rho_{\ell}=0$ implies that the value of unemployment consists solely of the monetary value of UI benefits. However, remember that the bargaining outcome is not affected by the choice of $\rho_{\ell}$ in this model. With $\rho_{\ell}=0$, the contribution of the UI benefit extensions to the unemployment rate is higher than the baseline result (1.4 percentage points) at 2.1 percentage points. At the same time, the response of the average duration of unemployment to a 1-week increase in the UI benefit duration is 0.2 , which is at the upper bound of the empirical estimates. This result is intuitive since a lower value of unemployment makes unemployed workers more desperate in their job search, especially as they remain unemployed for a long time or they are exhausting savings. $\rho_{\ell}=0.15$ generates a slightly stronger result than the baseline. Next, I change the borrowing constraint from the baseline value of $\underline{k}=-1000$ to -2000 and 0 . The contribution of the UI benefit extensions to the unemployment rate implied by the model is stronger (1.7 percentage points) when the borrowing limit is tighter $(\underline{k}=0)$, because the tight borrowing limit makes the unemployed more desperate to find a job in the initial steady state, and the UI benefit extensions make the unemployed less desperate more substantially than in the baseline. As expected, a less strict borrowing limit $(\underline{k}=-2000)$ implies a weaker contribution from the UI benefit extensions to the unemployment rate (1.3 percentage points). Finally, I change the parameter controlling the bargaining outcome from the baseline value of $\bar{\omega}=0.97$ to 0.95 . This implies larger profits for matched firms. The main results are found to be insensitive to this change.

In the bottom panel of Figure 5, I change the elasticity of the average wage with respect to changes in labor productivity from the baseline value of 0.449 , which is estimated by Hagedorn and Manovskii (2008). This change does not affect the steady state of the model, but the path of the time-varying aggregate productivity needs to be recalibrated such that the equilibrium path of the unemployment rate generated by the model tracks the empirical unemployment rate. The first experiment is to set $\epsilon_{w}=0$. Notice $\epsilon_{w}=0$ means that the average wage is constant. This experiment is inspired by a recent paper by Shimer (2011), who shows that real wages were rigid in the recent downturn. It turns out that the main result of the paper - the contribution of the UI benefit extensions to the unemployment rate - is not very sensitive to the assumption of wage rigidity. Second, I set $\epsilon=0.90$, which is twice as large as the baseline value. A high value of wage elasticity implies that the surplus of the firms, and thus the number of vacancy postings, moves less than in the baseline for the same change in aggregate productivity. In other words, the model has a weaker amplification mechanism, as in Shimer (2005). The contribution of the UI benefit extensions to the unemployment rate (1.5 percentage points) turns out to be similar to the baseline result of 1.4 percentage points. However, in order for the path of the unemployment rate to closely track its empirical counterpart, aggregate productivity has to drop by 7.3 percent instead of 1.1 percent, since the model lacks a strong amplification mechanism with flexible real wages. 


\section{Conclusion}

This paper quantifies the effect of extensions of UI benefits on the unemployment rate using a calibrated structural model that features job search and consumption-saving decisions, skill depreciation, UI eligibility, and a series of UI benefit extensions that capture the UI benefit extensions that have been enacted in response to the recent downturn. By using a structural model, I can capture the effect of the UI benefit extensions on the unemployment rate and other macroeconomic aggregates, properly taking into account the gradual and temporary nature of the recent extensions. Moreover, a structural model enables counterfactual experiments. I find that the extensions of UI benefits contributed to an increase in the unemployment rate of 1.4 percentage points, with a baseline conservative calibration. Since unemployment went up by 4.8 percentage points, from 4.8 percent during the period 2005-2007, before the recent downturn started, to 9.6 percent, which is the average during the period 2009-2011, the contribution of the series of UI benefit extensions is 29 percent. Among the remaining 3.4 percentage points, 2.5 percentage points are due to the large increase in the separation rate, while staggering aggregate productivity contributes 0.9 percentage point. Moreover, the contribution of the UI benefit extensions to the elevated unemployment rate increased from 2009 to 2011; while the number of vacancies has been recovering, the unemployment rate has remained elevated because of the successive extensions. I also find that the last extension has moderately slowed down the recovery of the unemployment rate. Specifically, the model indicates that the last extension keeps the unemployment rate higher by 0.6 percentage point during 2011. If another extension is enacted to replace the current one, similar effects on the unemployment rate would be expected.

Three directions of future research are worth mentioning. First, the model in this paper can be extended to a general equilibrium model with capital, the labor force participation decision, and the government budget constraint. The decline in the search effort has a general equilibrium effect, as employment declines while capital stock increases. Introducing the labor force participation decision also allows us to investigate the discouraged worker effect. The general equilibrium model in which the government must finance the UI benefits is suitable for answering the welfare effects of the UI benefit extensions. Second, the model can be used to study the optimal UI program. Although there are already numerous attempts to investigate the optimal UI program, using a more stylized model, an analysis with a carefully calibrated structural model has an advantage as the key to answering the question is to compare the relative importance of different effects. Finally, what is the optimal response of the UI policy to business cycles? Recently Landais et al. (2011) and Mitman and Rabinovich (2011) have come up with different answers to this important question. The business cycle version of the model developed in this paper, with rich features, can contribute to the discussion. 


\section{References}

Acemoglu, Daron and Robert Shimer, "Productivity Gains from Unemployment Insurance," European Economic Review, 2000, 44 (7), 1195-1224.

Bils, Mark, Yongsung Chang, and Sun-Bin Kim, "Worker Heterogeneity and Endogenous Separations in a Matching Model of Unemployment Fluctuations," American Economic Journal: Macroeconomics, 2011, 3 (1), 128-154.

Card, David and Phillip B. Levine, "Extended Benefits and the Duration of UI Spells: Evidence from the New Jersey Extended Benefit Program," Journal of Public Economics, 2000, 78 (1-2), $107-138$.

Chetty, Raj, "Moral Hazard vs. Liquidity and Optimal Unemployment Insurance," Journal of Political Economy, 2008, 116 (2), 173-234.

Conesa, Juan C. and Dirk Krueger, "Social Security Reform with Heterogeneous Agents," Review of Economic Dynamics, 1999, 2 (3), 757-795.

Costain, James S. and Michael Reiter, "Business Cycles, Unemployment Insurance, and the Calibration of Matching Models," 2006. University Pompeu Fabra Economics Working Paper No. 872.

Farber, Henry S., "Job Loss in the Great Recession: Historical Perspective from the Displaced Workers Survey, 1984-2010," National Bureau of Economic Research Working Paper, 2011, No. 17040.

Fujita, Shigeru, "Economic Effects of the Unemployment Insurance Benefits," Federal Reserve Bank of Philadelphia Business Review, 2010a, Fourth Quarter, 20-27.

_ , "Effects of the UI Benefit Extensions: Evidence from the CPS," 2010b. FRB Philadelphia Working Paper No. 10-35/R.

_ , "Declining Labor Turnover and Turbulence," 2011. Unpublished.

Gruber, Jonathan, "Unemployment Insurance, Consumption Smoothing, and Private Insurance: Evidence from the PSID and CEX," in Laurie J. Bassi and Stephen A. Woodbury, eds., Research in Employment Policy, Volume 1, Reform of the Unemployment Insurance System, Bingley, UK: Emerald Group Publishing Limited, 1998, pp. 3-32.

_ , "The Wealth of the Unemployed," Industrial and Labor Relations Review, 2001, 55 (1), 79-94.

Hagedorn, Marcus and Iourii Manovskii, "The Cyclical Behavior of Equilibrium Unemployment and Vacancies Revisited," American Economic Review, 2008, 98 (4), 1692-1706.

Hamermesh, Daniel S., Jobless Pay and the Economy, Baltimore, MD: Johns Hopkins University Press, 1977. 
Jacobson, Louis S., Robert J. LaLonde, and Daniel G. Sullivan, "Earnings Losses of Displaced Workers," American Economic Review, 1993, 83 (4), 685-709.

Kambourov, Gueorgui and Iourii Manovskii, "Occupational Specificity of Human Capital," International Economic Review, 2009, 50 (1), 63-115.

Katz, Lawrence F. and Bruce D. Meyer, "The Impact of the Potential Duration of Unemployment Benefits on the Duration of Unemployment," Journal of Public Economics, 1990, 41 (1), 45-72.

Krueger, Alan B. and Andreas Mueller, "Job Search and Unemployment Insurance: New Evidence from Time Use Data," Journal of Public Economics, 2010, 94 (3-4), 298-307.

_ and _, "Job Search, Emotional Well-Being and Job Finding in a Period of Mass Unemployment: Evidence from High-Frequency Longitudinal Data," Brookings Papers on Economic Activity, forthcoming.

Krusell, Per, Toshihiko Mukoyama, and Ayşegül Şahin, "Labor-Market Matching with Precautionary Savings and Aggregate Fluctuations," Review of Economic Studies, 2010, 77 (4), $1477-1507$.

Landais, Camille, Pascal Michaillat, and Emmanuel Saez, "Optimal Unemployment Insurance over the Business Cycle," National Bureau of Economic Research Working Paper, 2011, No. 16526.

Ljungqvist, Lars and Thomas J. Sargent, "The European Unemployment Dilemma," Journal of Political Economy, 1998, 106 (3), 514-550.

Meyer, Bruce D., "Unemployment Insurance and Unemployment Spells," Econometrica, 1990, $58(4), 757-782$.

Mitman, Kurt and Stan Rabinovich, "Pro-cyclical Unemployment Benefits? Optimal Policy in an Equilibrium Business Cycle Model," 2011. PIER Working Paper No. 11-010, University of Pennsylvania.

Moffitt, Robert, "Unemployment Insurance and the Distribution of Unemployment Spells," Journal of Econometrics, 1985, 28 (1), 85-101.

- and Walter Nicholson, "The Effect of Unemployment Insurance on Unemployment: The Case of Federal Supplemental Benefits," Review of Economics and Statistics, 1982, 64 (1), 1-11.

Mortensen, Dale T., "Unemployment Insurance and Job Search Decisions," Industrial and Labor Relations Review, 1977, 30 (4), 505-517.

Nakajima, Makoto, "Business Cycles in the Equilibrium Model of Labor Market Search and Self-Insurance," International Economic Review, forthcoming.

Petrongolo, Barbara and Christopher A. Pissarides, "Looking into the Black Box: A Survey of the Matching Function," Journal of Economic Literature, 2001, 39 (2), 390-431. 
Reichling, Felix, "Optimal Unemployment Insurance in Labor Market Equilibrium When Workers Can Self-Insure," 2007. Unpublished Manuscript.

Ríos-Rull, José-Víctor, "Computation of Equilibria in Heterogeneous-Agent Models," in Ramon Marimon and Andrew Scott, eds., Computational Methods for the Study of Economic Dynamics, Oxford: Oxford University Press, 1999, chapter 11.

Shimer, Robert, "The Cyclical Behavior of Equilibrium Unemployment and Vacancies," American Economic Review, 2005, 95 (1), 25-49.

_, "Wage Rigidities and Jobless Recoveries," 2011. Unpublished.

U.S. Department of Health and Human Services, "Indicators of Welfare Dependence: Annual Report to Congress," 2008.

Valletta, Rob and Katherine Kuang, "Extended Unemployment and UI Benefits," Federal Reserve Bank of San Francisco Economic Letter, 2010, 2010-12.

Whittaker, Julie, "Extending Unemployment Compensation Benefits During Recessions," Congressional Research Service Report, 2008, RL34340. 


\section{Appendix A Computational Appendix}

\section{A.1 Steady-State Equilibrium}

In the steady state, there is no UI benefit extension ( $x=0$ for all workers in all periods), and the separation rate $\lambda_{t}$ and aggregate productivity $z_{t}$ are constant at $\bar{\lambda}$ and $\bar{z}$, respectively. Computing a steady-state equilibrium amounts to finding value functions $W(0, h, u, a, k)$ and $F(h)$, optimal decision rules $g^{k}(0, h, u, a, k)$ and $g^{s}(0, h, u, a, k)$, time-invariant probability measure $\mu$, and the labor market tightness for each skill type $\left\{\theta^{h}\right\}$ that together satisfy the equilibrium conditions listed in Section 3.9. The detailed computational algorithm is as follows:

1. Set an initial guess of the labor market tightness $\left\{\theta^{h, 0}\right\}$.

2. Given $\left\{\theta^{h, 0}\right\}$, the job-finding rate per search effort $\left\{f^{h}\right\}$ and the matching probability per vacancy $\left\{d^{h}\right\}$ can be computed.

3. Given $\left\{f^{h}\right\}$, solve for the optimal value function for the worker $W(0, h, u, a, k)$. This step includes the following sub-steps.

(a) Set grid points on the space of $k \in[\underline{k}, \bar{k}]$ so that the value function for the worker and the optimal decision rules can be stored in a computer. $\underline{k}$ is given by the calibration. $\bar{k}$ is set such that it is never binding for the optimization problem of the worker.

(b) Set the initial guess for the value $W^{0}(0, h, u, a, k)$.

(c) Using $W^{0}(0, h, u, a, k)$ as the future value, update the value function using the Bellman equations (7) and (10) and obtain $W^{1}(0, h, u, a, k)$. In evaluating the future value function for $k^{\prime}$ not on one of the grid points, an interpolation is used. I use the shape-preserving spline interpolation.

(d) Check convergence. If the distance between $W^{0}(0, h, u, a, k)$ and $W^{1}(0, h, u, a, k)$ is smaller than the predetermined tolerance level, move on to the next step. The optimal decision rules $g^{k}(0, h, u, a, k)$ and $g^{s}(0, h, u, a, k)$ obtained in this step are the ones associated with the optimal value function. Otherwise, replace $W^{0}(0, h, u, a, k)$ by $W^{1}(0, h, u, a, k)$ and go back to step 3 (c).

4. Given $\left\{d^{h}\right\}$, solve for the optimal value function for the firm $F(h)$. This step includes the following sub-steps.

(a) Set the initial guess for the value $F^{0}(h)$.

(b) Using $F^{0}(h)$ as the future value, update the value function using the Bellman equation (13) and obtain $F^{1}(h)$.

(c) Check convergence. If the distance between $F^{0}(h)$ and $F^{1}(h)$ is smaller than the predetermined tolerance level, move on to the next step. Otherwise, replace $F^{0}(h)$ by $F^{1}(h)$ and go back to step 4 (b). 
5. With the job-finding rate $\left\{f^{h}\right\}$ and the optimal decision rules $g^{k}(0, h, u, a, k)$ and $g^{s}(0, h, u, a, k)$ at hand, simulate the economy until the type distribution converges to its stationary distribution. This step includes the following sub-steps.

(a) Discretize the space of asset holdings $k \in[\underline{k}, \bar{k}]$ so that the type distribution $\mu$ can be stored in a computer. Notice that the grids used to store $\mu$ can be (desirably) finer than the grids used to store the value function and the optimal decision rules. In case the grids used for $\mu$ are finer, use piecewise linear interpolation to evaluate the optimal decision rules over finer grids.

(b) Set the initial guess for the type distribution $\mu^{0}$.

(c) Use the transition probabilities for exogenous state variables, optimal decision rules $g^{k}(0, h, u, a, k)$ and $g^{s}(0, h, u, a, k)$, and the job-finding rate $\left\{f^{h}\right\}$, update the type distribution and obtain $\mu^{1}$. When the optimal decision $g^{k}(0, h, u, a, k)$ falls between two grid points, the measure is allocated proportionally to the adjacent two grid points.

(d) Check convergence. If the distance between $\mu^{0}$ and $\mu^{1}$ is smaller than the predetermined tolerance level, move on to the next step. Otherwise, replace $\mu^{0}$ by $\mu^{1}$ and go back to step 5 (c).

6. Update the labor market tightness and obtain $\left\{\theta^{h, 1}\right\}$ using the free entry condition (14), the stationary type distribution, and the optimal decision rules.

7. Check convergence. If the distance between $\left\{\theta^{h, 0}\right\}$ and $\left\{\theta^{h, 1}\right\}$ is smaller than the predetermined tolerance level, a steady-state equilibrium is obtained. Otherwise, update $\left\{\theta^{h, 0}\right\}$ by taking a weighted average of $\left\{\theta^{h, 0}\right\}$ and $\left\{\theta^{h, 1}\right\}$ and go back to step 2 .

The algorithm above is a general one, but thanks to the property of the model that the free entry condition can be simplified to (15), there is no need for iterations for the labor market tightness. Specifically, one can start by solving for the firm's value function, which together with (15) provides the equilibrium labor market tightness $\left\{\theta^{h}\right\}$. The last step is to solve for the optimal value function of workers, given the equilibrium $\left\{\theta^{h}\right\}$, which has already been obtained.

\section{A.2 Equilibrium with Deterministic Transition}

An equilibrium with transition between two steady states is solved, for example, in Conesa and Krueger (1999). The details of the computational algorithm are described in Ríos-Rull (1999). The model used in the current paper adds two novel features to existing models. First, there are multiple (indeed, nine) policy changes (UI benefit extensions) instead of the typical assumption of one policy change. Second, each policy change is announced in advance. I also assume that the government has a perfect commitment technology; the announcements are credible.

It is further assumed that all policy changes are temporary, in the sense that the economy after a policy change asymptotically reverts to the initial steady state. ${ }^{15}$ The value functions for

15 This assumption is easily relaxed. When a policy change has a permanent effect, the steady state associated with the permanent policy change must be computed in advance and used as the end point. 
workers and firms associated with the steady state are denoted as $W_{\infty}(0, h, u, a, k)$ and $F_{\infty}(h)$, respectively. As an approximation, it is assumed that the economy converges to the initial steady state in period $T$. For a good approximation, $T$ has to be a large number. It is also assumed that the economy starts from the initial steady state, and the type distribution in the initial steady state is denoted by $\mu_{0}$.

The economy starts from period 1, with the extension 0 (associated with no announced extension). Notice that, even without an extension announced, the time-varying separation rate and aggregate productivity are revealed, which makes the path of the economy start to diverge from its steady state. In general, it is possible to include a policy change in $j=0$. If there are $J$ policy changes (UI benefit extensions), $J+1$ sequences of the labor market tightness $(j=0,1,2, \ldots, J)$ need to be solved. A sequence of the labor market tightness associated with the policy change (UI benefit extension) $j$ is $\left\{\theta_{j, t}^{h}\right\}_{t=\tau_{j}}^{T}$. Notice that the history associated with the policy change $j$ starts from $\tau_{j}$, which is the period in which the new policy is announced. Also notice that the $\mathrm{j}$-th UI benefit extension is characterized by $x^{\prime}=\chi_{j, t}(x, u, a)$. The detailed computational algorithm is as follows:

1. Start from the extension $j=0$.

2. Set a guess for the sequence of the labor market tightness associated with the policy change $j,\left\{\theta_{j, t}^{h, 0}\right\}_{t=\tau_{j}}^{T}$.

3. Given a sequence $\left\{\theta_{j, t}^{h, 0}\right\}_{t=\tau_{j}}^{T}$, a sequence of the job-finding rate $\left\{f_{j, t}^{h}\right\}_{t=\tau_{j}}^{T}$ and a sequence of the matching probability per vacancy $\left\{d_{j, t}^{h}\right\}_{t=\tau_{j}}^{T}$ can be computed.

4. Solve for the value function for the workers $W_{j, t}(x, h, u, a, k)$ for $t=\tau_{j}, \tau_{j}+1, \ldots, T$. This step includes the following sub-steps.

(a) Let's start from the last period $(t=T)$. Since it is assumed that the economy converges to the initial steady state in period $T$, the value function in period $t+1$ is known: $W_{j, t+1}(x, h, u, a, k)=W_{\infty}(x, h, u, a, k)$.

(b) Using $W_{j, t+1}(x, h, u, a, k)$, the time-varying separation rate and aggregate productivity, the job-finding rate, and the UI benefit extension characterized by $\chi_{j, t}(x, u, a)$, update the value function using the Bellman equations (7) and (10) and obtain $W_{j, t}(x, h, u, a, k)$. The optimal decision rules $g_{j, t}^{k}(x, h, u, a, k)$ and $g_{j, t}^{s}(x, h, u, a, k)$ are obtained in the process.

(c) Keep going back until period $t=\tau_{j}$.

5. Starting from period $\tau_{j}$, simulate the economy until period $T$. This step includes the following sub-steps.

(a) Start from $t=\tau_{j}$. Set the initial type distribution $\mu_{j, t}=\mu_{j, \tau_{j}}$. In the case where $j=0$, it is the initial steady-state distribution $\mu_{0}$ by assumption. In the case where $j>0$, 
the initial steady state is obtained by the distribution associated with the policy $j-1$, i.e., $\mu_{j-1, \tau_{j}}$ adjusted by the UI benefit extension $\chi_{j, t}(x, u, a){ }^{16}$

(b) Update $\mu_{j, t}$ and obtain $\mu_{j, t+1}$, using the job-finding rate $\left\{f_{j, t}^{h}\right\}$, optimal decision rules $g_{j, t}^{k}(x, h, u, a, k)$ and $g_{j, t}^{s}(x, h, u, a, k)$, and stochastic processes for the exogenous state variables.

(c) Keep updating the distribution up to period $T$.

6. Update the sequence of the labor market tightness and obtain $\left\{\theta_{j, t}^{h, 1}\right\}_{t=\tau_{j}}^{T}$ using the free entry condition (14), the sequence of type distribution $\left\{\mu_{j, t}\right\}_{t=\tau_{j}}^{T}$, and the optimal decision rules.

7. Check convergence by comparing the sequence of the labor market tightness $\left\{\theta_{j, t}^{h, 0}\right\}_{t=\tau_{j}}^{T}$ and $\left\{\theta_{j, t}^{h, 1}\right\}_{t=\tau_{j}}^{T}$. If the distance between them is smaller than the predetermined tolerance level, an equilibrium associated with the policy change (UI benefit extensions) $j$ is obtained. Go to the next step. Otherwise, update $\left\{\theta_{j, t}^{h, 0}\right\}_{t=\tau_{j}}^{T}$ by taking a weighted average of $\left\{\theta_{j, t}^{h, 0}\right\}_{t=\tau_{j}}^{T}$ and $\left\{\theta_{j, t}^{h, 1}\right\}_{t=\tau_{j}}^{T}$ and go back to step 3 .

8. If an equilibrium sequence of the labor market tightness for all $j=0,1, . ., J$ is obtained, go to the next step. Otherwise, go back to step 2 for a new $j=j+1$.

9. Once an equilibrium associated with all policy changes (all UI benefit extensions) is computed, the actual path of the economy can be obtained. The actual history of the economy is obtained by combining the periods $\left\{\tau_{j}, \tau_{j}+1, \ldots \tau_{j+1}-1\right\}$ for all $j=0,1, \ldots, J$, with $\tau_{J+1}=T+1$.

Let me make two remarks. First, notice that the problem can be simplified in the same way as described for the algorithm to compute a steady-state equilibrium. Basically, there is no need for iterations for the labor market tightness. In particular, one can solve for the firm's value function and the equilibrium labor market tightness $\left(\left\{\theta_{j, t}^{h}\right\}_{t=\tau_{j}}^{T}\right.$ for $\left.j=0,1, \ldots, J\right)$ without solving the worker's problem. Once the equilibrium labor market tightness is obtained, worker's value function and optimal decision rules can be solved. Second, it is straightforward to see that the equilibrium with a one-time policy change without prior announcement, which is used by Conesa and Krueger (1999) and many others, is a special case with $J=0, \tau_{0}=\widetilde{\tau}_{0}=1$ and the policy change implemented in period 1.

\footnotetext{
$\overline{16}$ The extension changes the distribution, in particular of $x$, only when the extension is implemented without prior announcement.
} 